\title{
Global distribution and surface activity of macromolecules in offline simulations of marine organic chemistry
}

\author{
Oluwaseun O. Ogunro $\cdot$ Susannah M. Burrows $\cdot$ Scott Elliott $\cdot$ \\ Amanda A. Frossard • Forrest Hoffman • Robert T. Letscher · \\ J. Keith Moore $\cdot$ Lynn M. Russell $\cdot$ Shanlin Wang • Oliver W. Wingenter
}

Received: 9 September 2014/ Accepted: 28 August 2015/Published online: 13 October 2015

(C) The Author(s) 2015. This article is published with open access at Springerlink.com

\begin{abstract}
Organic macromolecules constitute a high percentage of remote sea spray. They enter the atmosphere through adsorption onto bubbles followed by bursting at the ocean surface, and go on to influence the chemistry of the fine mode aerosol. We present a global estimate of mixed-layer macromolecular distributions, driven by offline marine systems model output. The approach permits estimation of oceanic concentrations and bubble film surface coverages for several classes of organic compound. Mixed layer levels are computed from the output of a global ocean ecodynamics model by relating the macromolecules to standard biogeochemical tracers. Steady state is assumed for labile forms, and for longer-lived
\end{abstract}

Responsible Editor: Mark Brush.

O. O. Ogunro · O. W. Wingenter

New Mexico Institute of Mining and Technology,

Socorro, NM 87801, USA

S. M. Burrows

Pacific Northwest National Laboratory, Richland,

WA 99354, USA

S. Elliott $(\bowtie) \cdot$ S. Wang

Los Alamos National Laboratory, Los Alamos,

NM 87545, USA

e-mail: sme@lanl.gov

A. A. Frossard - L. M. Russell

Scripps Institution of Oceanography, La Jolla, CA 92093, USA components we rely on ratios to existing transported variables. Adsorption is then represented through conventional Langmuir isotherms, with equilibria deduced from laboratory analogs. Open water concentrations locally exceed one micromolar carbon for the total of proteins, polysaccharides and refractory heteropolycondensates. The shorter-lived lipids remain confined to regions of strong biological activity. Results are evaluated against available measurements for all compound types, and agreement is generally well within an order of magnitude. Global distributions are further estimated for both fractional coverage of bubble films at the air-water interface and the two-dimensional concentration excess. Overall, we show that macromolecular mapping provides a novel tool for the comprehension of oceanic surfactant patterns. These results may prove useful in planning

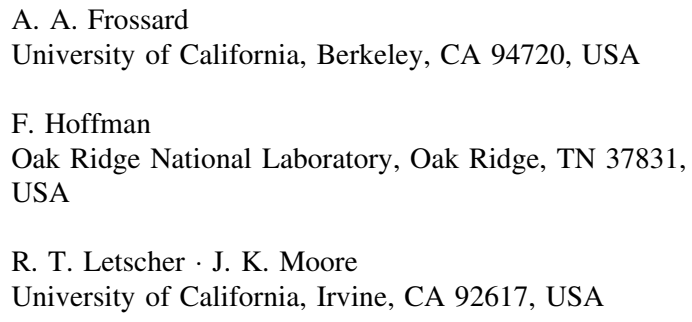


field experiments and assessing the potential response of surface chemical behaviors to global change.

Keywords Organic macromolecules - Mixed layer distributions · Langmuir adsorption · Fractional coverage $\cdot$ Bubble films $\cdot$ Air-water interface

\section{Introduction}

Organic carbon is now regularly reported as a ubiquitous natural constituent during observations of the sub-micron marine aerosol (O'Dowd et al. 2004; Russell et al. 2010; Lapina et al. 2011). Macromolecules of biological origin can be conveyed vertically through the ocean mixed layer to the sea surface microlayer by several mechanisms: upwelling in the general circulation, attachment to air bubbles, and association with buoyant exopolymeric particles (Cunliffe et al. 2011; Wurl et al. 2011). Bubble bursting at the ocean surface produces nascent sea spray aerosol droplets; this is a major process capable of transferring organic matter from ocean water into the marine boundary layer (Russell et al. 2010; Cunliffe et al. 2011). Emitted aerosol particles containing long-chain carbon molecules can contribute significantly to the atmospheric particle population and affect the concentrations of cloud condensation nuclei (CCN; Meskhidze et al. 2011). The CCN in turn influence cloud formation and development, with impacts on climate through modification of the albedo.

Aerosol processes currently represent a poorlyunderstood component of the global biogeochemical system, leading to major uncertainties in radiative forcing as presented in recent climate assessments (Solomon et al. 2007). Natural emissions lie at the heart of this issue, including sources from marine biogenic carbon which extend over much of the planet. Total aerosol forcing has shifted significantly across the globe since the industrial revolution, but the largest uncertainties are associated with the quantification of naturally occurring particles (Carslaw et al. 2013). The oceanic contribution is dominant in terms of coverage area. Fluxes of seawater organics into the remote aerosol system may evolve significantly over the next few decades (O'Dowd et al. 2004; Meskhidze et al. 2011). Changes must be considered both in local mass transfer rates and the regional influence of biogeography. The prediction of future distributions of macromolecules and surfactants will require simultaneous consideration of biological, chemical and physical mechanisms affecting the introduction and enrichment of organic matter.

The fraction of organic material emitted to the atmosphere in fine mode sea spray has recently been parameterized for global atmospheric models as a function of the satellite-observed ocean chlorophyll-a concentration (Vignati et al. 2010; Lapina et al. 2011; Meskhidze et al. 2011). The approach is sometimes augmented by a dependence on wind speed (Gantt et al. 2011) or particle size (Long et al. 2011). In these representations, chlorophyll acts as a proxy for the marine ecodynamic processes that are more fundamentally responsible for the generation of high molecular weight substances. Here we present preliminary tests of an alternative technique, which accounts more completely for macromolecular chemical resolution within the sea (Benner 2002) and then utilizes the distributions to predict the organic mass composition in fine-mode sea spray aerosol (Burrows et al. 2014). The following quantities are explored as offline carbon additions to a global marine biogeochemical model: proteins, polysaccharides, lipids, certain aminosugar derivatives and especially peptidoglycan, heteropolycondensate byproducts in the mixed layer, and the humics of central water masses.

We work from previously simulated values of primary production, phytoplankton distributions and generic dissolved organic matter. Our base model is the Biogeochemistry-Ecosystem-Circulation package for ecological dynamics (Moore et al. 2004). This code runs as a standard module inside the Parallel Ocean Program and it is also a subcomponent of the Community Earth System Model. Our aim is to develop and test surface ocean biogeochemical schemes capable of speciating dissolved organic carbon into macromolecular and polymeric subclasses. Attempts are also made to deal with heterogeneous molecular recombination processes and oligomeric decay products, in at least a preliminary fashion. To indicate zones of potential influence for the individual organic compounds, we additionally estimate and map Langmuir adsorptiondriven surface coverage. The results can be applied conceptually to any of the several air-water interface types residing near the atmospheric boundary, including wave-generated bubble films and the global sea surface microlayer. The resolved concentrations that we generate are evaluated against several specific types 
of chemical oceanographic measurement. Finally, interpretations are offered for the simulated global patterns, both in terms of surfactant coverage and also the chemically resolved carbon excess.

\section{Background}

Chemical oceanographers first divided the large scale dissolved organic fraction into its macromolecular constituency in roughly the 1970s. Consideration of the potential surfactant effects began at about the same time. As might be expected, structures known to exist inside phytoplanktonic and microbial cells were quickly identified as fresh release forms (Lee and Bada 1977; Gagosian and Stuermer 1977). Organic films were simultaneously documented at the multiple water-air interface types (Garrett 1967; Hoffman and Duce 1976). Analytical techniques demanded by such studies were quite challenging, since diverse functional groups had to be distinguished and/or separated from the heterogeneous ionic medium that is seawater. Nonetheless progress has been steady -contrast the reviews by Liss (1975) and then Liss et al. (1997) as an instructive set of examples. Highlights during this period of growth in the laboratory and seagoing effort have included the elucidation of bubble surface chemistry (Blanchard 1975, 1989), recognition of the importance of polymeric colloidal/gel processing (Wells and Goldberg 1993; Chin et al. 1998), and transfer effects of films on sea-air gas fluxes (Frew et al. 1990; Tsai and Liu 2003).

It should be clear from this brief history that major concepts underlying the present work have been explored by a range of research groups operating over several decades. But planetary scale marine systems models have only been widely available since just prior to the turn of the century. Tracer lists are now long enough to begin distinguishing the dissolved organics in an idealized manner. Initially the perspective of the overall carbon cycle has most often been adopted, with discrimination mainly according to reactivity or lability (e.g. Moore et al. 2004; Hansell et al. 2012). Our contribution is to attempt a functionally realistic representation of individual macromolecules, so that surfactant properties can be intercompared. We achieve this working from a family of intermediate complexity ecodynamics models already incorporating a subset of reactive organic precursors (Moore et al. 2002, 2004).

General and oceanographic surface film literatures have been mined to provide for the required theoretical information. A brief list of sample references might include Ter Minassian-Seraga (1956) on surfactant kinetics; Adamson (1960) offering a classic textbook approach to the two dimensional physical chemistry; Somorjai (1972) which is a complementary text but stronger in some ways and particularly with regard to adsorption enthalpy and temperature dependence; Liss (1975) which is among the first comprehensive reviews in the marine microlayer literature and nicely introduces the concept of ocean surface pressure; Barger and Means (1985) as an illustrative first attempt to develop interfacial equations of state from a coastal point of view. Laboratory investigations have also been scanned over the last few decades for relevant equilibrium data, and useful examples may be found in the Graham and Phillips (1979) study of stock proteins functioning as surfactants; Adamson and Gast (1997) reviewing some of the more modern adsorption research; Baeza et al. (2005) on interactions in the equilibrated multicomponent state; Moore et al. (2008) focusing on coastal and Gulf Stream humics; and finally Brzozowska et al. (2012) in which the kinetic concepts of Ter Minassian-Seraga (1956) are updated for natural salt water systems.

Results of this preparation process can be summarized through equations describing first the distributions and then surfactant behaviors of the various marine lipid and polymer classes. What follows is in fact a strong condensation from earlier presentations by our own group (Elliott et al. 2014; Burrows et al. 2014). In these publications we emphasized respectively, the time evolution of surface film structures for a few key ecological provinces and then the potential mechanisms of adsorptive transfer from bubbles into the aerosol. In the current work, we extend the effort by outlining a global marine mixed layer or chemical oceanographic viewpoint for the first time. It is also the case that previous approaches relied on the simplest possible molecular proxies. Mainly we restricted ourselves to familiar, pure macromolecules and avoided any mixed functionalities. Here the aminosugars and heterogeneous oligomers/polymers are treated in somewhat more detail. 


\section{Methods: assumptions and equations}

Our strategy is to blend a contemporary marine biogeochemical knowledge base with fundamental aspects of surfactant theory. Through this combination we seek to better define the properties of a major environmental interface - the boundary between sea and air, which is nominally unbroken but complicated by the formation of bubble and atmospheric particle plumes (Liss 1975; Blanchard 1989; Russell et al. 2010). We build from the output of a well-established ocean systems model (Moore et al. 2002, 2004; Elliott et al. 2011; Wang et al. 2015). This baseline code utilizes a simulated fluid dynamic general circulation to transport resources into the sunlit euphotic zone. There they support fixation of carbon from dissolved inorganic to particulate forms including pigments. Distributions for upwelling nutrients plus those of the carbonates and other small molecules are verifiable by soundings gathered into rich large-scale data sets (e.g. World Ocean Atlas and others at nodc.noaa.gov). Phytoplanktonic chlorophyll has been monitored in surface waters for several decades via remote sensing (Longhurst 1998; oceancolor.gsfc.nasa.gov), while detailed trophic dynamics including zooplankton counts can be compared with about half a dozen time series obtained at oceanographic stations (Moore et al. 2002).

Given this strong backdrop of metrics and data comparison, reliance on a biogeochemical model involves at least two primary assumptions -fidelity in under-sampled surface ecosystems, and also for tracer distributions in underlying water. Effectively, we apply the validated global driver code as a sophisticated interpolation tool. Elemental cycles are extended into lesser-known mixed layer situations or else downward through the column, to depths from which refractory organics sometimes convect (Dittmar and Kattner 2003; Moore et al. 2004). Remote sensing has only begun to distinguish major classes of the biota, so additionally we depend on computations for local taxonomy. This is of greatest importance for chitin, and certain other amino polysaccharides generated mainly by the prokaryotes (Benner 2002; Benner and Kaiser 2003; Aluwihare et al. 2005; Kaiser and Benner 2009). Populations of the producers themselves may be highly variable, so that crosschecking of the resulting concentrations is essential.

Our physical chemical approach is by contrast quite generic. The surfactant studies we draw upon have deep historical roots going back more than a century. Both textbooks and recent environmental studies cite Langmuir-Blodgett trough experiments of the early nineteen hundreds as a baseline (Adamson and Gast 1997; Svenningsson et al. 2006; Tuckermann 2007; Fuentes et al. 2010). The familiar approximation of an idealized monolayer must be made in order to translate laboratory results to global ocean interfaces -dissolved material must accumulate along atmospheric boundaries in a manner described at least in part by linear saturation (Elliott et al. 2014). Liquid phase surface tension measurements are then readily interpretable. The concepts recur regularly in the marine microlayer literature (Liss 1975; Barger and Means 1985; Frew et al. 1990; Kujawinsky et al. 2002) and also concerning the behavior of organics in tropospheric aerosol droplets (Blanchard 1975, 1989; Svenningsson et al. 2006; Meskhidze et al. 2011; Burrows et al. 2014). It thus seems logical to use Langmuir theory as a chemical bridge from ocean to atmosphere. Monolayer behavior will of course break down near the point of full coverage due to intermolecular interactions, and at high two dimensional pressures as the condensed phase collapses (Adamson 1960; Graham and Phillips 1979). But our hypothesis is that nonetheless, textbook surface chemistry should capture the basics of adsorptive equilibration along with intermolecular site competition.

In the equation set to follow, low level theory is presented incorporating all these approximations. We deal first with macromolecular reactive transport in the global modeling context, then with the tendency for organics to adhere to bubble fields. Coherent mixed layer distributions are defined for a subset of marine surfactant proxies, working from biogeochemical simulations of the broader reservoir of dissolved organic carbon. Simple Langmuir style computation is applied with thermochemical parameters held constant, even in the regime approaching or surpassing total coverage. Both the biogeochemical and surfactant models are of necessity incomplete, but we maintain that they nonetheless constitute appropriate starting points. Implications of our major assumptions are explored further after a full exposition of results, in the concluding discussion section.

Organic compound distribution estimates are built up primarily from the global marine ecodynamics framework known as BEC, standing for Biogeochemistry-Ecosystem-Circulation (Moore et al. 2004; Letscher et al. 2015; Wang et al. 2015). This code 
simulates multielement flow through several trophic levels in the upper ocean, with limitations by the usual nutrient types and light availability. Competitions are included for about half a dozen different phytoplankton classes. Consumers are represented as a single agglomerate zooplankton weighted between microand mesoscale forms depending on the balance of food items. Heterotrophic bacteria are represented only as a time constant acting on dissolved organics in order to remineralize them. Thus the microbial recyclers are not carried in BEC explicitly. Since they are actually critical to the production of certain combined polysaccharide-proteins, we adapt a convenient parameterization from earlier work on sulfur biogenic aerosol sources (Elliott 2009). All ecodynamics are embedded in the Parallel Ocean Program or POP in order to provide a transport context or in other words, global current and mixing fields (Moore et al. 2004). Emphasis in the original code family is placed upon primary production and traditional inorganic carbonate chemistry. The relevant parameters, source-sink terms and ordinary differential equations are described in the main appendix of Moore et al. (2002). Critical routings for the dissolved organics are developed further in Moore et al. (2004).

BEC ecodynamic tracer fields are imported into our calculations directly from the most recent versions, incorporating improvements which mainly involve phytoplankton-specific parameter settings (Wang et al. 2015). Our treatment of the organics involves streamlined parallel kinetics operating conceptually on high molecular weight chains portrayed as individual forms of carbon. We do not attempt to conserve the other major atom types. Relevant high molecular weight compounds are released primarily by the disruption of autotrophic cells (Wakeham et al. 1997; Kujawinsky et al. 2002), with exudation appended in some cases (Benner 2002; Elliott et al. 2014). Thus injection patterns are determined by a combination of primary and secondary production inherited from the driver program. But the various lipids and polymers are all given distinct, functionally specific residence times. In most cases these refer to disappearance, with only a nominal allowance for interchange among polymer types or the accumulation of refractories (Carlson 2002; Nagata et al. 2003).

The notation here derives from our ice algal equation set (Elliott et al. 2012, 2015), but it is tailored to the processing of POP history files. A vector of macromolecular carbon quantities $\boldsymbol{C}_{\text {mac }}$ or individually $C_{i}$ is generated from BEC autotrophic carbon concentrations $\boldsymbol{C}^{\text {phyto }}\left(C^{p}\right)$ through a short series of manipulations. The phytoplanktonic index is positioned as a superscript because it can be dropped as soon as total injections are collected. An intermediate step is apportionment of the long chain compounds within producer cells, based on a commonly accepted global average breakdown (Parsons et al. 1984; Wakeham et al. 1997; Benner 2002). Values are very consistent across the literature at 60, 20 and 20 percent for the major, fresh organic types protein, polysaccharide and lipid $(f$ for $\mathrm{i}=1-3)$. A disruption rate constant subscripted by dis $r$ is estimated from the local BEC mortality and zooplankton levels, so that macromolecular spill rate patterns can be computed. Together these stages in the processing may be summarized as

$C_{i}^{p}=f_{i} C^{p} ; \quad$ Spill $_{i}=\sum_{p} k_{d i s r}^{p} C_{i}^{p}$

Model and mapping calculations are performed in units of $\mu \mathrm{M}$ carbon, with ecodynamic flow carried in $\mu \mathrm{M} / \mathrm{d}$ in all cases. For the first three compound types rough time constants are next selected, characterizing the extent to which material is transported from its point of origin. A significant fraction of the lipidic mass tends to be short lived relative to horizontal mixing (Kattner et al. 1983; Parrish et al. 1992). The aliphatics are therefore handled at local steady state. Some polysaccharides by contrast survive on the order of months and are transported outward to the regional scale (Wakeham et al. 1997; Goldberg et al. 2009). BEC semilabile dissolved organics constitute an overlapping tracer set (Moore et al. 2004) and so we assign an adjustable but major portion to act as a surrogate for the carbohydrates. The proteins are often classified as intermediate in stability (Wakeham et al. 1997) and in this early simulation we represent them merely as an average of the other two macromolecules. In order of actual computation then,

$$
\begin{gathered}
C_{\text {lip }}=\operatorname{Spill}_{\text {lip }} \tau_{\text {lip }} ; C_{\text {poly }}=f_{\text {semi }} C_{\text {semi }}(B E C) \\
C_{\text {prot }}=\left(C_{\text {lip }}+C_{\text {poly }}\right) / 2
\end{gathered}
$$

Here indices become abbreviations in the interest of readability, and our choices should be self-explanatory (prot, poly, lip). Chemical structures which are independent of phytoplanktonic injection are dealt with as special cases. For example peptidoglycan is 
relatively short lived as a combined polymer (Nagata et al. 2003) so that once again a steady state approximation is reasonable. But heterotrophic bacteria are assumed to comprise the major source, and their distributions have to be estimated from earlier sulfur cycle simulations (Elliott 2009 shown as E09). A significant fraction of net carbon cycling through the microbial loop can be assigned, since the polymer is a major component of bacterial cell walls (Benner and Kaiser 2003). The proportion $f_{\text {pept }}$ is therefore varied around a central value of ten percent to achieve agreement with in situ data. Hence an additional relationship is required:

$C_{\text {pept }}=f_{\text {pept }}$ Loop $_{\text {micr }}\left(\right.$ E09) $\tau_{\text {pept }}$

The quantity Loop is just another form of elemental flow. Heteropolycondensates are computed by difference relative to the global field of total dissolved organics (Hansell et al. 2012). This is accomplished by subtracting the sum of results 1 through 3 from the contemporary total carbon distribution. Implicitly then, mixed functionality compounds represent the accumulation of dissolved detritus (Benner 2002). Humic acid is estimated based on the Arctic central layer concentrations provided by Dittmar and Kattner (2003), which are likely representative of water masses below the thermocline (Benner 2002; Hansell et al. 2012). Zones where winter vertical convection penetrates deeply are identified from the three dimensional general circulation model output. All of the time constants and concepts employed in the above equations are condensed for reference in Table 1.

Surface interactions of the marine macromolecules distributed by Eqs. 1-3 are determined according to, and represented by, idealized two dimensional chemistry on the Gibbs phase plane (Adamson 1960; Somorjai 1972). A thermochemical system coupling Langmuir monolayer formation with the surface tension parameterization of Szyszkowski is adopted as the primary model. Its potential for interpreting marine surfactant behaviors is apparent from widespread application to environmental organics including lipids, freshly released biomacromolecules, oxidation products and hydrolytic derivatives (Graham and Phillips 1979; Svenningsson et al. 2006; Tuckermann 2007; Moore et al. 2008). Selected experimental data are shown in Table 2, then translated into mapping information for the planetary scale interfaces lying between sea and air. The latter include not only the perimeter of wave driven bubbles, but also the global microlayer and even the nascent spray aerosol early in its evolution. Our intention however is to work first and foremost from a bottom up or chemical oceanographic perspective. The reader is referred to Elliott et al. (2014) plus Burrows et al. (2014) for detailed treatments extending into the atmospheric boundary layer.

Thermochemical reference forms are as follows: The biomacromolecules and sea salt act as solutes, the solvent water surrounds them, and a subset of organics resides at the interface. The latter potentially equilibrate as far as the gas phase. Given bulk liquid and gaseous mixtures of $j$ components, total moles and the Gibbs free energy are both readily expressible as sums. But the mass of surfactants is explicitly accounted such that rearrangement isolates the quantities of interest on the left hand side. They are superscripted just below with the word "Surface".

$n_{j}^{l}+n_{j}^{g}+n_{j}^{\text {Surface }}=n_{j} ; \quad G^{l}+G^{g}+G^{\text {Surface }}=G$

$n_{j}^{\text {Surface }}=n_{j}-\left(n_{j}^{l}+n_{j}^{g}\right) ;$
$G^{\text {Surface }}=G-\left(G^{l}+G^{g}\right)$

A differential change in free energy is given by

$d G=-S d T+V d p+\sigma d A+\sum_{j} \mu_{j} d n_{j}$

where $\sigma$ is the surface tension in units, for example, of $\mathrm{N} / \mathrm{m}$ or $\mathrm{J} / \mathrm{m}^{2}$ and other symbols have their usual meanings. The surface energy contribution is additive in 6 upon the standard textbook $d G$. Under local conditions in the marine aqueous system, temperature may be considered constant. Furthermore the volume of the dividing plane is zero by definition (Adamson 1960; Tuckermann 2007). Since all chemical potentials must be in balance at equilibrium, the expression for surface free energy change simplifies and is readily integrated.

$$
\begin{aligned}
& \mu_{j}^{\text {Surface }}=\mu_{j}^{l}=\mu_{j}^{g} \\
& d G^{\text {Surface }}=\sigma d A+\sum_{j} \mu_{j} d n_{j}^{\text {Surface }} ; \\
& G^{\text {Surface }}=\sigma A+\sum_{j} \mu_{j} n_{j}^{\text {Surface }}
\end{aligned}
$$

The tension is a quantity often measured by surface chemists and in fact it is involved in most of the 
Table 1 Schematic mechanism for the production and transformation of specified macromolecular categories, in mixed and central layers of the global ocean

\begin{tabular}{lllll}
\hline Class & Source & Time constant & Products & References \\
\hline Protein & Phytoplankton & 10 days & AA, Hetpc & Nagata et al. (2003), Tanoue (1992) \\
Polysaccharide & Phytoplankton & 100 days & Sugars, Hetpc & Goldberg et al. (2009), Hansell et al. (2012) \\
Lipid & Phytoplankton & 1 day & CH in Hetpc & Parrish et al. (1992) \\
Chitin & Zooplankton & Insoluble & Chitosan, lysates & Aluwihare et al. (2005), Benner and Kaiser (2003) \\
Peptidoglycan & Prokaryotes & 30 days & Glucosamine & Benner and Kaiser (2003), Nagata et al. (2003) \\
Heteropoly & All products & Refractory & Humics & Benner (2002), Hansell et al. (2012), Wells (2002) \\
Humic Acid & Abyssal & Refractory & Final & Dittmar and Kattner (2003)
\end{tabular}

$A A$ the marine amino acids, $C H$ alkyl functionality, Hetpc or Heteropoly heteropolycondensates comprising a processed, dissolved organic carbon background

Table 2 Surfactant behaviors for macromolecular model compounds

\begin{tabular}{lllll}
\hline Class & Model Species & $C_{1 / 2}$ & $\Gamma_{\max }$ & References \\
\hline Protein & Lysozyme & $\sim 10^{-4}$ & $1-10(1)$ & Graham and Phillips (1979) \\
Polysaccharide & Alginate & $>10^{-1}$ & $1-100(10)$ & Babak et al. (2000) \\
Lipid & Stearic Acid & $<10^{-6}$ & $1(1)$ & Brzozowska et al. (2012), Christodoulou and Rosano (1968) \\
Chitin & Chitin & Insoluble & & Kumar (2000) \\
Peptidoglycan & GAGP & $\sim 10^{-2}$ & $1-100(10)$ & Benner and Kaiser (2003), Damodaran and Razumovsky (2003) \\
Heteropoly & Gulf Stream & $\sim 10^{-1}$ & $1-10(1)$ & Moore et al. (2008) \\
Humic acid & Riverine Fulvic & $\sim 10^{-2}$ & $1-10(1)$ & Svenningsson et al. (2006) \\
\hline
\end{tabular}

Half saturation concentrations for Langmuir isothermal surface coverage are given in molar units $\left(C_{1 / 2}\right)$, and the associated maximum excess or two dimensional concentration is expressed for convenience as carbon atoms per square angstrom

GAGP gum Arabic glycoprotein, present along with the gum polysaccharide as an impurity. Heteropoly see Table 1

Table 2 determinations. Working from 4 to 8 the value of $\sigma$ can now be understood as a function of composition. The product rule and Gibbs-Duhemtype arguments provide the key relationship, after matching with earlier expressions. If we exclude all surfactants but the macromolecules, subscript $j$ reduces to $i$ since these are the only substances with a two dimensional presence.

$$
\begin{gathered}
d G^{\text {Surface }}=\sigma d A+A d \sigma+\sum_{i} n_{i}^{\text {Surface }} d \mu_{i} \\
+\sum_{i} \mu_{i} d n_{i}^{\text {Surface }} \\
A d \sigma=-\sum_{i} n_{i}^{\text {Surface }} d \mu_{i}
\end{gathered}
$$

At this point we focus for purposes of clarity on a single unnamed organic which may be of oceanographic interest. The summation is no longer needed and moles are converted into an analog of concentration, $\Gamma=n / A$.
Typically this quantity is referred to as the "excess", because it is not accounted for in the aqueous phase. It will be computed and plotted once the relevant Langmuir equilibria and competitions are fully developed. In the present work we alternately apply units of carbon atoms per square angstrom and moles per square meter, in order to visualize the surfactant situation at the microscopic scale or else in the context of standard seawater salinity.

For any dilute solute, chemical potential is related to the logarithm of concentration $C$. In all the critical cases here, we will refer to local levels of the dissolved carbon atoms from Eqs. 1-3. Various useful forms of the Gibbs surface equation are:

$$
\begin{gathered}
d \sigma=-\Gamma d \mu ; d \mu=R T d \ln C \\
d \sigma / d C=-\Gamma R T / C
\end{gathered}
$$

In weak solutions, a linear approximation may be invoked and macromolecules necessarily exert a 
lowering influence on the interfacial tension. Surface pressure $\Pi$ is typically defined as the difference in $\sigma$ from pure to water-solute situations.

$$
\begin{gathered}
\sigma=\sigma^{*}+\text {-const.C } ; \quad \Pi=\text { const. } C \\
d \sigma / d C=- \text { const } ; \quad \Pi=\Gamma R T
\end{gathered}
$$

Expression 12 is sometimes referred to as the "two dimensional ideal gas law" since back-substitution of the excess yields $\Pi A=n R T$ (Liss 1975; Barger and Means 1985). In principle, some combination of 11 with the simple "law" might be used to model the behavior of hypothetical marine surfactants. But the idealized relationships often break down under ambient conditions. They are most appropriate to point solutes/adsorbers lacking structure and molecular interaction (Graham and Phillips 1979; Tuckermann 2007; Elliott et al. 2014).

The Gibbs equation combines conveniently with results from adsorption kinetics to yield a fit to the tension curve in the region of growing surfactant influence (Somorjai 1972). Rates of site occupation and desorption are given by $k_{a} C$, where the proportionality constant has units of per (concentration time), and $k_{d}$ in the reverse direction which is first order. Fractional coverage $\theta$ is then a function of the ratio between the two, and this in turn may be thought of as an adsorptive equilibrium constant. Its reciprocal is just the concentration at half coverage $C_{1 / 2}$. We rely heavily on half saturation as a reference point while organizing laboratory surfactant data.

$K=k_{a} / k_{d} ; \quad \theta=K C /(1+K C) ; \quad C_{1 / 2}=K^{-1}$

An assymptote for monolayer coverage or excess $\Gamma_{\max }$ may also be assumed, although even this is not a given as polymers reconfigure, stack and react (Adamson 1960; Graham and Phillips 1979). A particularly compact mathematical form is then attained. Substitution and integration yield what is often called the Langmuir-Szyszkowski equation, after major contributors working in the early era.

$$
\begin{aligned}
& \Gamma=\Gamma_{\max } \theta=\Gamma_{\max } K C /(1+K C) \\
& d \sigma=-\Gamma R T d C / C ; \\
& d \sigma=-\Gamma_{\max } K R T(d C /(1+K C)) \\
& \Pi=\Gamma_{\max } R T \ln (1+K C)
\end{aligned}
$$

The two dimensional equilibrium constants represented in Table 2 were obtained by fitting surface tension or pressure data to the forms in 11-16, with one exception. Stearic acid is sufficiently insoluble in seawater that a kinetic dissolution approach had to be applied (Ter Minassian-Seraga 1956; Brzozowska et al. 2012). Note that in the table, reciprocal equilibria are expressed in pure molar units as opposed to the model/simulation standard of $\mu \mathrm{M}$. Values for limiting areal concentrations are often reported in $\mathrm{mg} / \mathrm{m}^{2}$ but we convert to our own dimensions for visualization and then oceanographic application. The $\Gamma_{\max }$ may also be derived by curve fitting but are measurable directly, by weighing out a particular sample then generating the spread film on a flat water surface (Adamson 1960; Graham and Phillips 1979; Damodaran and Razumovsky 2003).

When the distinctions " $i$ " are maintained and propagated beyond Eqs. 9-10 in order to represent multiple adsorbing agents, competition for the available interfacial surface area enters in (Somorjai 1972; Tuckermann 2007; Burrows et al. 2014). Multicomponent coverage can be described by the chemically resolved forms

$$
\begin{aligned}
& \theta_{k}=K_{k} C_{k} /\left(1+\sum_{i} K_{i} C_{i}\right) \\
& \theta_{\text {total }}=\sum_{k} \theta_{k} ; \quad \Gamma_{k}=\Gamma_{\max , \mathrm{k}} \theta_{k}
\end{aligned}
$$

where the final subscript $k$ is introduced to specify a single compound type. This is merely to distinguish intercomparisons among our marine organics from the overall components $j$ of the hypothetical aqueous-to-gas reference state in 4 and 5 . The derivation once again involves kinetic approach to (and desorption from) the water-air interface. It is sometimes provided in detail in physical chemistry source books (e.g. Laidler 1965). Ultimately the metrics collected in 17 are computed globally, to assess tradeoffs between selected biomacromolecules functioning as surfactants. But it should be clear from our development that at the level of chemical thermodynamics, the methods are quite approximate.

\section{Distributing the macromolecules}

Concentration mapping exercises were conducted offline relative to geocycling output from the BEC model running inside of the Community Earth System 
Model (Moore et al. 2004). Our calculations build on on a recent time-slice simulation of the marine methane cycle (Elliott et al. 2011) by utilizing major biotic and seawater composition outputs in an analysis and plotting script. Biogeochemical relationships adopted for the present work have been summarized in Eqs. 1 through 3 with time constants provide in Table 1. Our offline model is written in the NOAA Ferret scripting language, and it is available from the authors on request. More detailed descriptions appear in companion manuscripts emphasizing a few well studied ecosystems plus an atmospheric viewpoint involving the estimation of aerosol organic fractions (Elliott et al. 2014; Burrows et al. 2014). The complete global mechanism has been published as a Los Alamos COSIM technical report (Climate Ocean Sea Ice Modeling).

The preexisting external model partitions total chlorophyll into the major phytoplanktonic classes: small autotrophs $(0.2-2 \mu \mathrm{m})$, diazotrophs, coccolithophores, diatoms and high-latitude Phaeocystis. In the present work, we additionally represented intermediate competitors including the chlorophytes in order to extend the $C^{p}$ vector, along with cyanobacteria and heterotrophic bacteria in some tests (Gregg et al. 2003; Elliott 2009). These additional types may act as distinct specialist producers of certain surface active polymers. In some regional ecosystems, fibers and external cell barriers are synthesized as long rigid strands or even chemical grids. Thus we also introduced chitin and peptigoglycan as carbon sources associated with the cell perimeter. To achieve the biological resolution required for estimation of these polymers, two further steps were taken. Small autotrophs were apportioned post hoc using an alternate ecodynamic framework (Gregg et al. 2003), and a steady-state concentration of consumer microbes was computed according to the algorithm previously developed for dimethyl sulfide.

Polysaccharides may be considered relatively longlived among ocean organics (Goldberg et al. 2011), and so their distributions were represented as a constant fraction $f_{\text {semi }}$ of the moderately or semi-labile dissolved organic carbon imported from BEC. Many lipids lie at the opposite, reactive end of the macromolecular spectrum (Kattner et al. 1983). They are removed from the water column by heterotrophic bacteria sufficiently rapidly that their concentrations can be represented at local steady state. Proteins are often of intermediate stability, so they are computed in the current work simply as a weighted average of the previous two classes (Wakeham et al. 1997). Our approach can thus be thought of as a conceptual parallel steady state, but simultaneously it is tailored to the necessities of an offline mapping analysis. The balance between actual and indirect kinetics is dictated by the equations in 2 . For the polymeric categories carbohydrate and protein which are closely linked to dynamic output, we assume only implicitly that release is a byproduct of phytoplanktonic cell breakage. Hence the values are entirely consistent with processing in the parent routines (grazing, viral attack or senescence; Moore et al. 2004). Arguments in the dissolved organic literature often suggest that cell disruption is a major source channel for such fresh biomacromolecules (Kujawinsky et al. 2002; Kuznetsova et al. 2004; Kaiser and Benner 2009). Lipid production rates on the other hand were calculated fully explicitly, based on fixed BEC zooplankton and grazing fields. The carbon proportion of fatty acids and sterols was therefore estimated more directly, at the global average for phytoplanktonic composition determined by $f_{\text {lip }}$. Photochemical production is known for certain species in the organic spectrum including aliphatics (Benner 2002), but it is not considered at this point in our research.

We further assessed diatomaceous and zooplanktonic (copepod) sources for the structural material chitin, a common acetylated aminopolysaccharide. It is produced both for purposes of protective coverage and as a component of fibrils. Distributions were essentially determined by habitat and succession. It may be concluded, however, that this particular decay series is unlikely to support adsorptive coverage of water-to-air interfaces at the global scale. Chitin is a very insoluble polymer (Bhosle et al. 1998; Kumar 2000), and source-receptor logic applied to large scale monosugar observations indicates that solute release is weak (Benner and Kaiser 2003). Essentially, we argue from an empirical standpoint that this macromolecule is present at only trace levels across the surface ocean, at least in its dissolved form. By contrast peptidoglycan and its byproduct oligomers are reported as common components of open seawater (Benner and Kaiser 2003; Nagata et al. 2003; Aluwihare et al. 2005). In this instance, dissolved concentrations were estimated as a fraction of carbon flow through heterotrophic bacterial consumption channels (the microbial loop). Yields were adjusted to match both 
the reported concentrations and reactivity (Eq. 3, Nagata et al. 2003). Prokaryotic cyanophytes may also be producers of peptidoglycan, but in the interest of simplicity we defer their simulation here.

Organics injected by cell disruption as protein, polysaccharide and lipid are degraded in the ocean via random enzymatic and photochemical processes, into a massive but poorly known reservoir which is functionally mixed and polymeric (Benner 2002). We refer to such byproducts here collectively as the heteropolycondensates (Wells 2002). The material may be visualized as a combination of monomers, substituents and functional groups derived from the multiple source pools (Malcolm 1990). But it has been mapped solely as a difference quantity, relative to either independent or BEC estimates of the dissolved carbon total. The full complement of mixed layer macromolecules including proteins through heterogeneous polymers may further be incorporated at high latitudes into several modes of deep water formation. Through dark reactions at depth, conversion takes place into material that is essentially recalcitrant to chemical breakdown. Lifetimes may be comparable to residence times in the abyss (Dittmar and Kattner 2003), and in some cases they exceed thousands of years.

The deep carbon returns to the surface annually due to convective mixing in the winter hemisphere. Upward transport is estimated here for zones of high-latitude turnover based on numerical mixed-layer depths output along with the POP general circulation. Maximization tends to occur in an extremely geographically variable manner. We assumed complete vertical dilution of all constituents from the lower mixing limit at several hundred meters all the way to the surface. Results were then checked against climatological seasonal cycles and penetration depths compiled in an authoritative biogeography of the sea (Longhurst 1998). Humic acid concentrations were set equal to Arctic measurement data, presumed here to be representative of global high latitudes (Dittmar and Kattner 2003). Since we deduce central ocean humate from observations, source distributions are included in principle. Nonidentified, extrahumic amphiphiles were not simulated.

References in the final column of Table 1 are included as a guide to more comprehensive materials, for biogeochemical channels and time scales dictating the distributions of all macromolecular categories: generalized proteins (Tanoue 1992), carbohydrates comprising a portion of the traditional semi-labile dissolved organic carbon (Goldberg et al. 2009; Hansell et al. 2012) and the relatively short-lived lipids (Parrish et al. 1992). Aminosugar reactions in the mixed layer include hydrolysis leading to de-acetylation, the loss of amide linkages and decay of any substituent peptide appendages (Benner and Kaiser 2003; Nagata et al. 2003; Aluwihare et al. 2005). Like other processes under consideration, these are parameterized and hence treated in aggregate. More detailed structural definitions for the heteropolycondensate tracer are available in the literature regarding refractory and colloidal carbon (Wells 2002; Dittmar and Kattner 2003).

\section{Adsorption in the model}

Surfactants dissolved in the upper few meters of the ocean will adsorb readily to any air-water phase boundaries. Hence they are expected to coat the exterior of wave-generated bubbles and also liquid (aqueous) sections of the sea-air interface (Cunliffe et al. 2011). From these starting points, macromolecules may be emitted rapidly to the atmosphere following film breakage at the upper limit of the water column (O’Dowd et al. 2004; Russell et al. 2010). Per our final equation set 17 , standard multispecies Langmuir adsorption provides approximate coverages while multiplication by the laboratory maximum excess allows for conversion to areal concentrations. We represent surfactant processes in this simple way along all global airwater interfaces, i.e. the ocean surface microlayer and cavity interiors. Rising bubbles transport high molecular weight organics vertically, and additional material is attached at the end of the upward trajectory during passage into the atmosphere (Burrows et al. 2014). Along these pathways, relative amounts of the various macromolecules should be conveyed conservatively into nascent spray particles since timescales are short and no chemical reactions are postulated. Thus our maps are also relevant to the period prior to the onset of atmospheric photochemical degradation and formation of secondary organic aerosol.

Surfactant data are presented in Table 2 for a series of proxy compounds corresponding to the selected list of macromolecules. Most quantities were extracted directly from laboratory experiments, drawing upon the Gibbs-Langmuir-Szyszkowski relationships of Eqs. 11-16. Denatured proteins are represented by the hydrolytic catalyst lysozyme (Graham and Phillips 
1979). This particular structure is actually of terrestrial origin. But its adsorptive behaviors should largely be independent of any intracellular function. Polysaccharides may be very insoluble when hydrophobic substituents are attached. We adopt the synthetic analog alginate as an initial proxy for the class of pure polysaccharides (Babak et al. 2000). Lipids may be well represented either by long chain fatty acids or sterols (Kattner et al. 1983; Loh et al. 2008). Here we assign the role to stearate (Christodoulou and Rosano 1968; Brzozowska et al. 2012), with the option to switch to cholesterol.

Chitin, one of the most common polysaccharides in the ocean, is an example of high insolubility (Bhosle et al. 1998; Kumar 2000). Although hypothetical derivatives might prove to be adsorptive, we momentarily discount the contribution of this particular carbon decay line on a mass flow basis. The proteosubstituted amino sugars may be more surface active due to hydrophobic side group effects. In the absence of data, glycoproteins extracted from a well-known food stabilizer (gum arabic) are cited as a peptidoglycan analog (Damodaran and Razumovsky 2003). Heteropolycondensates and humics are discussed in the environmental chemistry literature primarily as coastal samples. Gulf Stream and commercial fulvics are taken to be representative (Svenningsson et al. 2006; Moore et al. 2008). Half saturations are listed in the table as $C_{1 / 2}$ for conceptual convenience, but in fact they can also be thought of as reciprocal equilibrium constants $K^{-1}$ following 13. As in the case of other parameters, coverage levels were derived assuming ideal dilute surfactant behavior. And all equilibria are uncertain by perhaps an order of magnitude, since real macromolecules exhibit significant deviations from the assumptions of Gibbs theory (Graham and Phillips 1979; Baeza et al. 2005; Shogren and Biresaw 2007).

Upward transport on the buoyant global bubble field will necessarily be modulated by the surface excess. This is just the density of material associated with unit adsorption area, as defined in the logic leading to Eqs. 17. For some substances of interest, the maximum is about one when expressed in units of atoms per square angstrom (Christodoulou and Rosano 1968; Graham and Phillips 1979). This value constitutes a useful conceptual starting point, because one side of the reference area is about the length of a carbon-carbon bond. But in several cases we recommend a range of areal concentrations, and these deserve additional comment. In controlled experiments, model heterogeneous polymers tend to form irregular and extremely complex structures spanning the water interface. Chains or filaments of hydrophiles may be suspended below a few hydrophobic constituents lining the surface (Babak et al. 2000; Damodaran and Razumovsky 2003; Moore et al. 2008). Stacked configurations could also be present in the marine environment, and so they are included here for potential sensitivity testing.

\section{Results: concentration distributions}

The concentration calculations are presented as a series of plots for the chosen macromolecular carbon types, each displaying panels from the four seasons. Monthly average distributions are shown for central months beginning with February representing winter, and arranged clockwise from upper left. Marine macromolecular compounds are discussed in the usual order, with protein, polysaccharide, lipid, peptidoglycan, heteropolycondensate products and finally the deep humics organized as Figs. 1, 2, 3, 4, 5, 6. We begin our analysis in all cases with austral summer. Ring ecosystems of the Southern Ocean are the most extensive and intense on the planet (Longhurst 1998). But winter deep convection is more pronounced and visually interesting in the Arctic regime than it is in the Antarctic. Our interpretations move equator-ward within the February plots, and then advance in time through the annual cycle. Typically, the northern hemispheric results follow similar trends that are merely delayed by 6 months.

Seasonal protein distributions are displayed in Fig. 1. As expected, patterns mimic those of primary production or generalized marine biological activity. The ecodynamic sequence of phytoplanktonic growth followed by cell disruption is primarily responsible for the release of fresh bioorganic molecules. Proteins are thought to be relatively short lived (Tanoue 1992; Goldberg et al. 2009; Hansell et al. 2012), so that their concentrations are a relatively small fraction of total dissolved organic carbon. Values in the central gyres fall in the $\mu \mathrm{M}$ range, but since the Langmuir adsorption reference point is small (Table 2), contributions to the surface chemistry may still be expected in the baseline configuration. Extremes in the Sunda-Arafura shelf province (Indonesia to New Guinea; Longhurst 

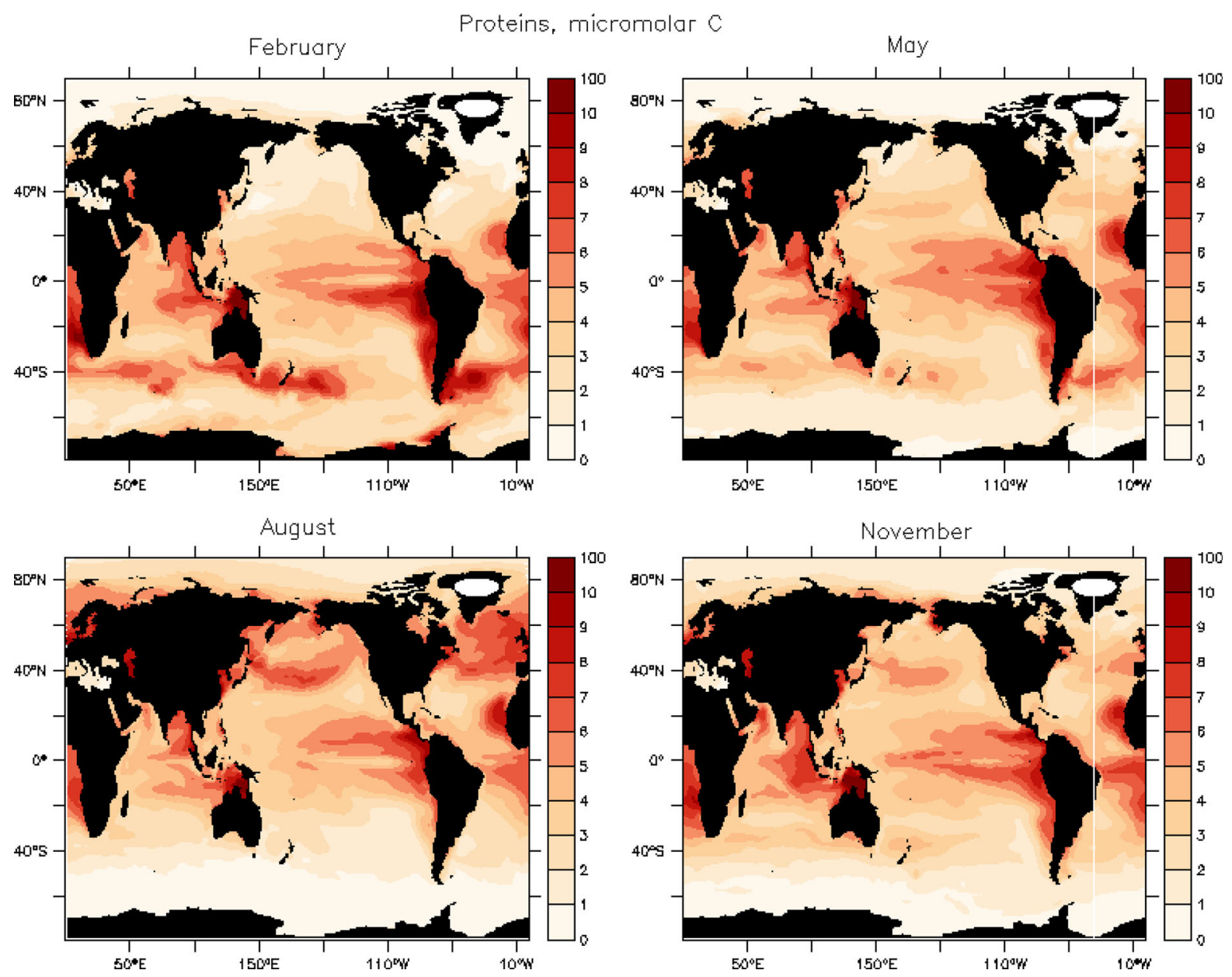

Fig. 1 Global surface ocean protein distributions estimated by our offline mapping procedure, central months of the four seasons. Units are micromolar $(\mu \mathrm{M})$ dissolved carbon

1998) can be attributed to stagnation and a corresponding buildup of semilabile material in the parent model (Moore et al. 2004). Proceeding through the seasons, a shift in protein steady state follows the path of the sun northward then returning. This fundamental cycle is common to several of the compounds studied here. An exception will be refractory carbon sourced from the abyss.

Patterns are similar for the polysaccharides as shown in Fig. 2, but concentrations are several times higher locally (note the change in color scale). These are realistic relative levels (Benner 2002; Hansell et al. 2012), and they reflect in part the differential lifetimes from Table 1. Maximal concentrations of the pure carbohydrate class amount to tens of $\mu \mathrm{M}$. This result is nominally consistent with measurements of neutral sugars conducted at key sites such as the major oceanographic stations (Goldberg et al. 2009, 2011), since they tend to be located within or at the edges of oligotrophic gyres. In certain areas, it is likely that serious overestimation of polysaccharide concentrations is occurring. The Arafura shelf again stands out, but maxima are also evident in the Humboldt Current extending all the way to coastal Peru. Eastern basin upwelling zones are relatively understudied for their organic chemistry in the Southern Hemisphere, but fractions approaching half of all dissolved organic carbon must be considered suspect. Similar concerns apply to the Canary Islands ecosystem during northern summer and in the far eastern Pacific off Central America. This potential problem can be traced to our oversimplification of reactive transport, since we 


\section{Polysaccharides, micromolar $\mathrm{C}$}
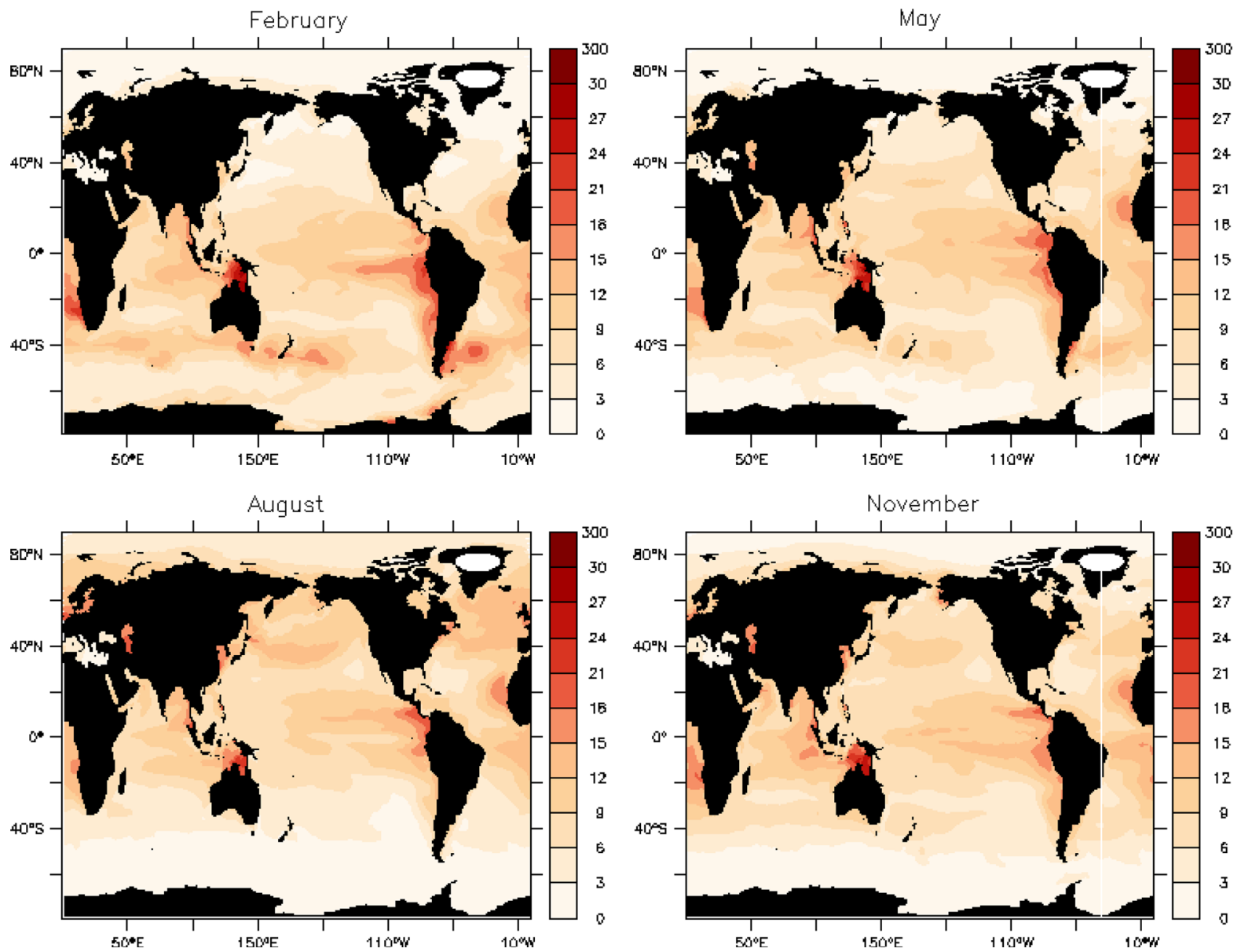

Fig. 2 Global surface ocean polysaccharide distributions estimated by our offline mapping procedure, central months of the four seasons. Units are micromolar $(\mu \mathrm{M})$ dissolved carbon

currently describe polysaccharides as a constant proportion of BEC semilabiles (Moore et al. 2004). It is likely the issues can be resolved when the macromolecules are simulated online within the general circulation.

Lipids are treated as a highly labile fraction here, so their concentrations are associated with primary production. The Falkland Islands and Subantarctic Ring zones are particularly prominent in the February panel of Fig. 3. Significant activity is also predicted for peripheral embayments surrounding the Antarctic continent and extending along the Palmer Peninsula. This effect may partially be explained by the coincidence of our monthly average plotting strategy with the mid-summer peak in polar biological activity (Longhurst 1998). The ice domain and receding pack edge, however, are often sites for strong blooms, whether for the diatoms or competing Phaeocystis. In the Antarctic polar provincial ecosystems, biological activity accelerates as ice coverage melts back toward the continent and the day lengthens moving into summer. Only negligible concentrations of lipid material are simulated at low latitudes in the global open ocean, but all members of this organic class are strong surfactants (Brzozowska et al. 2012), so that our exercise will ultimately lead to significant net coverage estimates in many areas. In northern hemispheric summer, the bloom fans out around and below the Arctic pack. Algal concentrations are probably overpredicted in this circumstance, but it is interesting to note that the lipids closely follow.

Our initial attempt to represent the amino polysaccharides adopts the bacterial cell wall component 

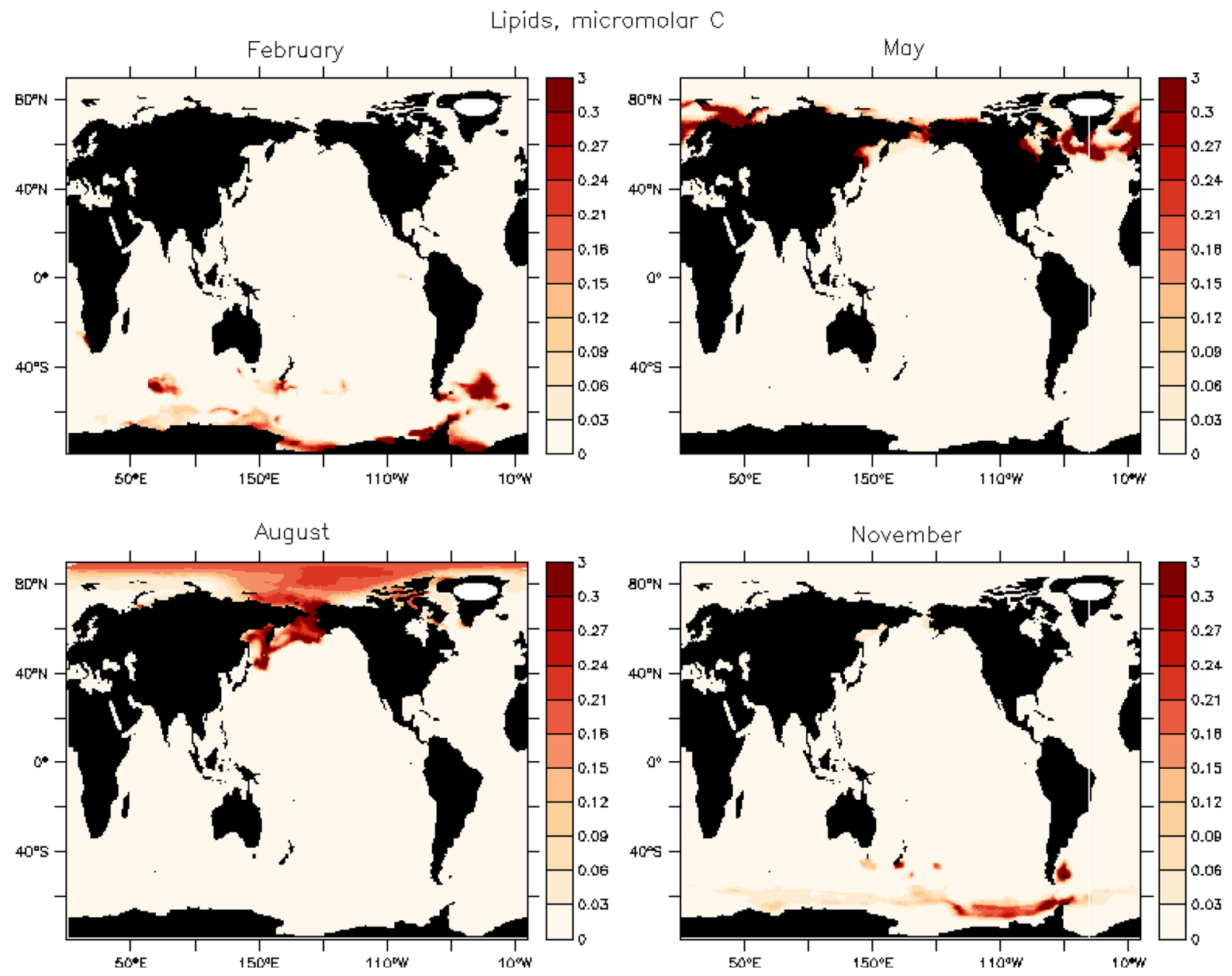

Fig. 3 Global surface ocean lipid distributions estimated by our offline mapping procedure, central months of the four seasons. Units are micromolar $(\mu \mathrm{M})$ dissolved carbon

peptidoglycan as a model (Fig. 4). Production of this external structural compound was computed in proportion to heterotrophic biomass density, and the latter was taken in turn from a parameterization developed to consume organic sulfur (Elliott 2009). Peptide substituent arms of the polymer are thought to degrade in only a few days, but the core oligosaccharide chain lasts much longer (Nagata et al. 2003). Still, we simulate the distribution as a local steady state, and in most areas of the global surface ocean this should serve as an adequate entry point. The production rate was adjusted to produce an average concentration of about one $\mu \mathrm{M}$ in keeping with the few available measurements (Benner and Kaiser 2003). But the microbial input was limited to ten percent of total carbon flow (Eq. 3). Concentration distributions of peptidoglycan are the most uniform among all compounds dealt with here. This is because the source is linked to recycling as opposed to primary production. The relationship we derive is approximately proportional to the square root of phytoplanktonic biomass (Parsons et al. 1984). Indications are that the aminosugars will congregate in zones of stronger upwelling. Plus once again the annual cycle is driven in all areas by season and solar angle. Like the lipids, aminated polymers tend to track their ecodynamic forcings below the Arctic pack during the melt (August). In this case however, the driver organisms are prokaryotic.

Heteropolycondensates will ultimately be treated in marine organic chemistry simulations as true recombination products. Here, we estimate their distributions mainly by invoking mass balance and difference 

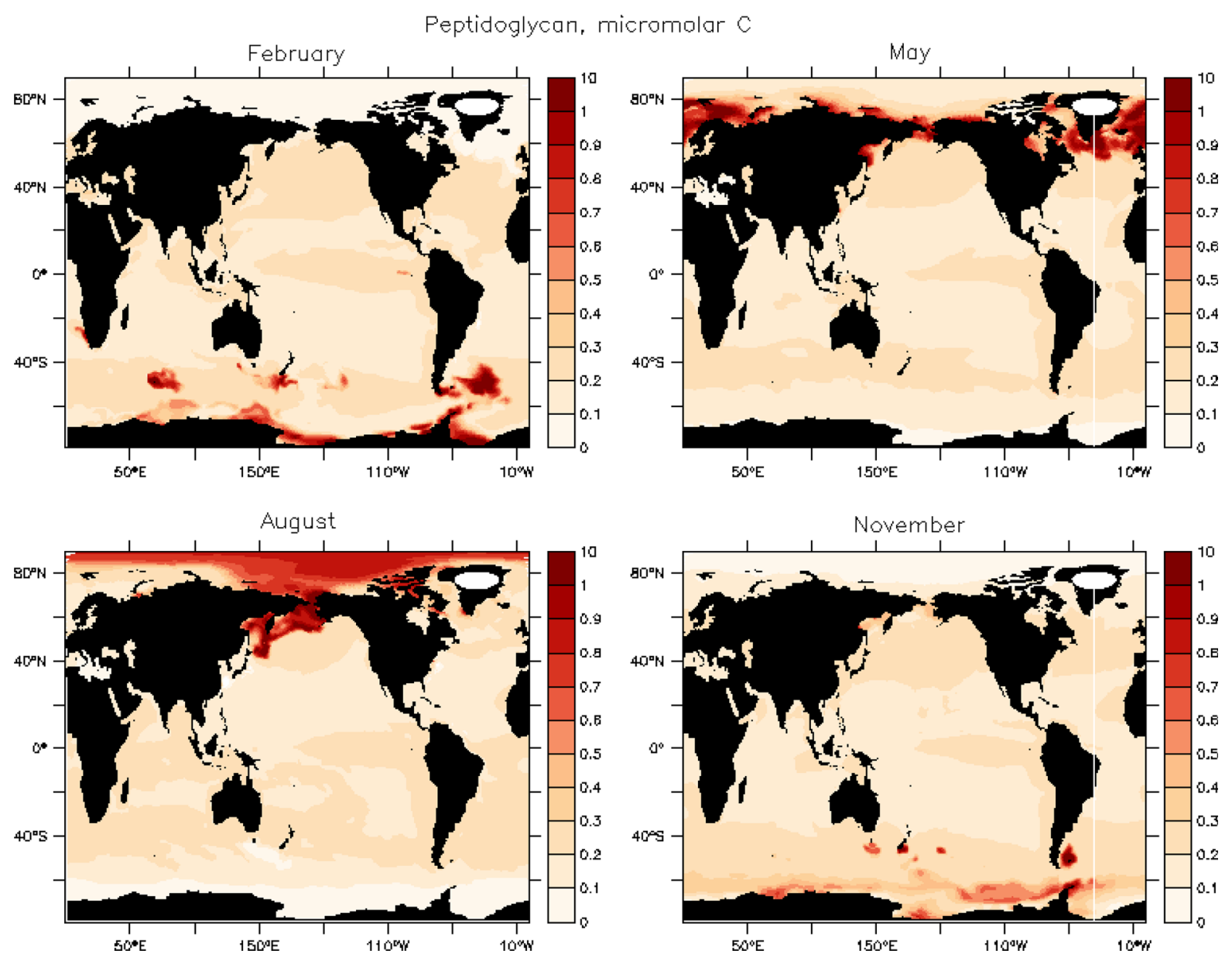

Fig. 4 Global surface ocean peptidoglycan distributions estimated by our offline mapping procedure, central months of the four seasons. Units are micromolar $(\mu \mathrm{M})$ dissolved carbon

relative to total dissolved organic carbon (Hansell et al. 2012). We have also compared results with dynamic simulations of real surface refractories, conducted online inside the BEC code but only recently available. The two approaches lead to consistent patterns, and the heterogeneous carbon distribution shown in Fig. 5 is representative. Areas of high concentration tend to be anticorrelated with those of the fresh macromolecules discussed above, because the heterogeneous material is produced exclusively by carbon degradation. But the molecules build to high levels of tens $\mu \mathrm{M}$, approaching the total of dissolved organic carbon concentration within the central gyres. This is because refractory residence times assumed in the model exceed surface ocean horizontal mixing periods. Accumulation in the gyres is thus the rule for this material. Stark minima in some locations should be discounted as an artifact of the differencing procedure. We believe this to be the case between Indonesia and Australia, and probably also in the Eastern South Pacific and the Atlantic Canary Islands province. The effect is likely real in the high Arctic, however, since there it is attributable to deep convective mixing.

Winter overturning acts as a major source of humic acid in the final concentration distributions presented in Fig. 6. In the Northern Hemisphere, deep water penetration is focused in the Labrador and GIN Seas (Greenland-Iceland-Norway; Longhurst 1998). Here, our offline model dilutes the remnant mixed layer and then partially replaces surface organics with deep humic substance (Benner 2002; Dittmar and Kattner 2003). Like the heteropolycondensates, humic acids are of mixed functionality. But they must still be 

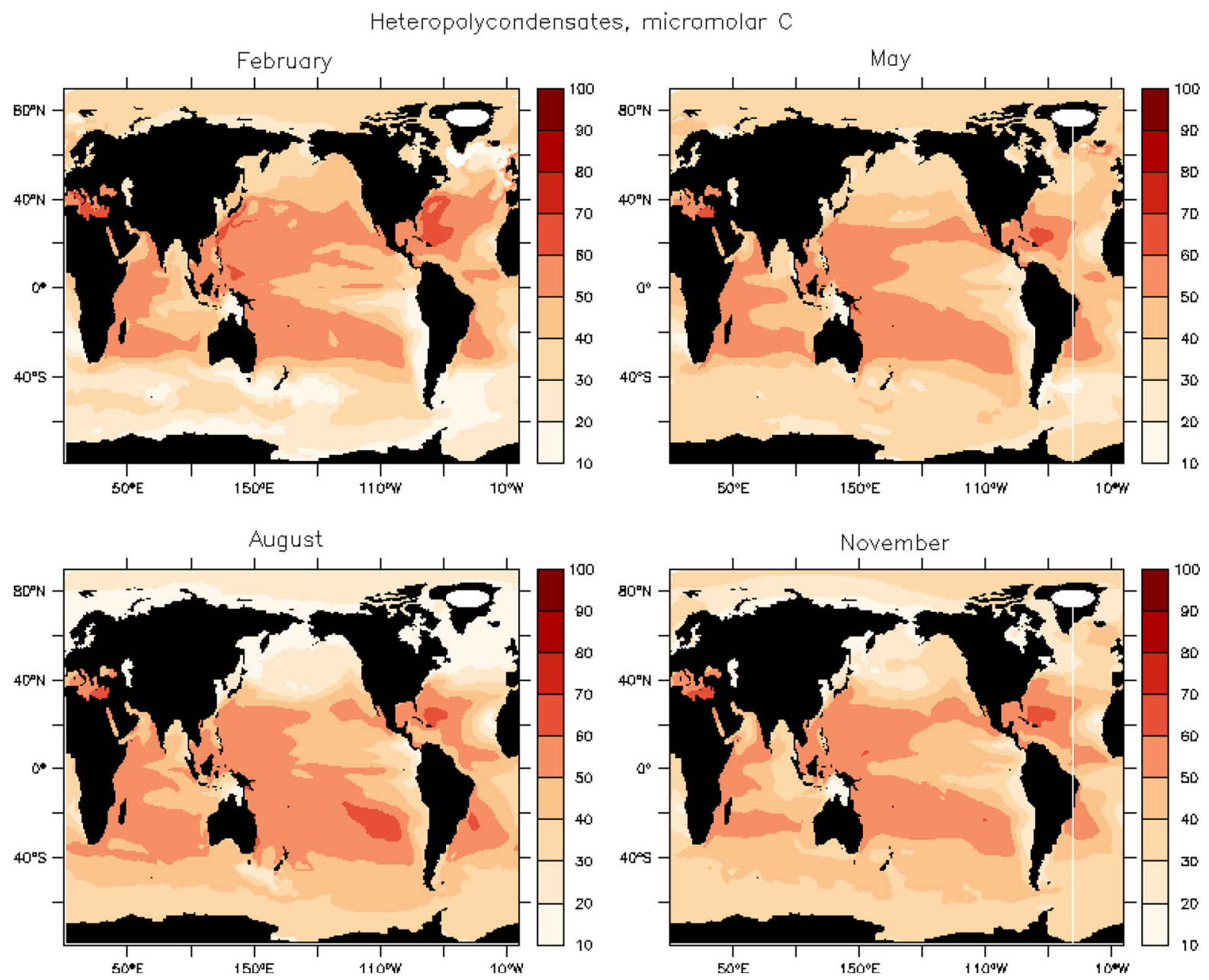

Fig. 5 Global surface ocean heteropolycondensate distributions estimated by our offline mapping procedure, central months of the four seasons. Units are micromolar $(\mu \mathrm{M})$ dissolved carbon

considered chemically distinct, due to long isolation from photochemical processing. The abyssal carbon is stirred to the surface, and there it displaces any constituents remaining from the peak of summer biological activity. Humics do not appear to be strongly surface active (Svenningsson et al. 2006), but the high North Atlantic is especially windy in the wintertime and aerosol effects may persist and propagate into early spring (O'Dowd et al. 2004). Concentrations of upwelled carbon at the surface approach the levels assigned in the present work for central water layers (i.e. depths of 200 meters). The value is set at $50 \mu \mathrm{M}$ (Dittmar and Kattner 2003). In the corresponding August plot, it is apparent that deep convection is less extensive in the Southern Ocean. Circumpolar current systems block high-salinity water masses which might otherwise be injected toward the pole from lower latitudes by the several western boundary currents (Longhurst 1998). POP results suggest that the strongest activity occurs along the southern frontal regime of the Tasman Sea.

\section{Data comparisons}

The maps of Figs. 1, 2, 3, 4, 5, 6 can now be checked against regional scale in situ observations across the global ocean. Serious caveats apply to such comparisons and must be mentioned to begin. Mainly the difficulties are attributable to complexities of the wet chemistry. Methods sections in the measurement papers of Table 3 reveal that samples may be 

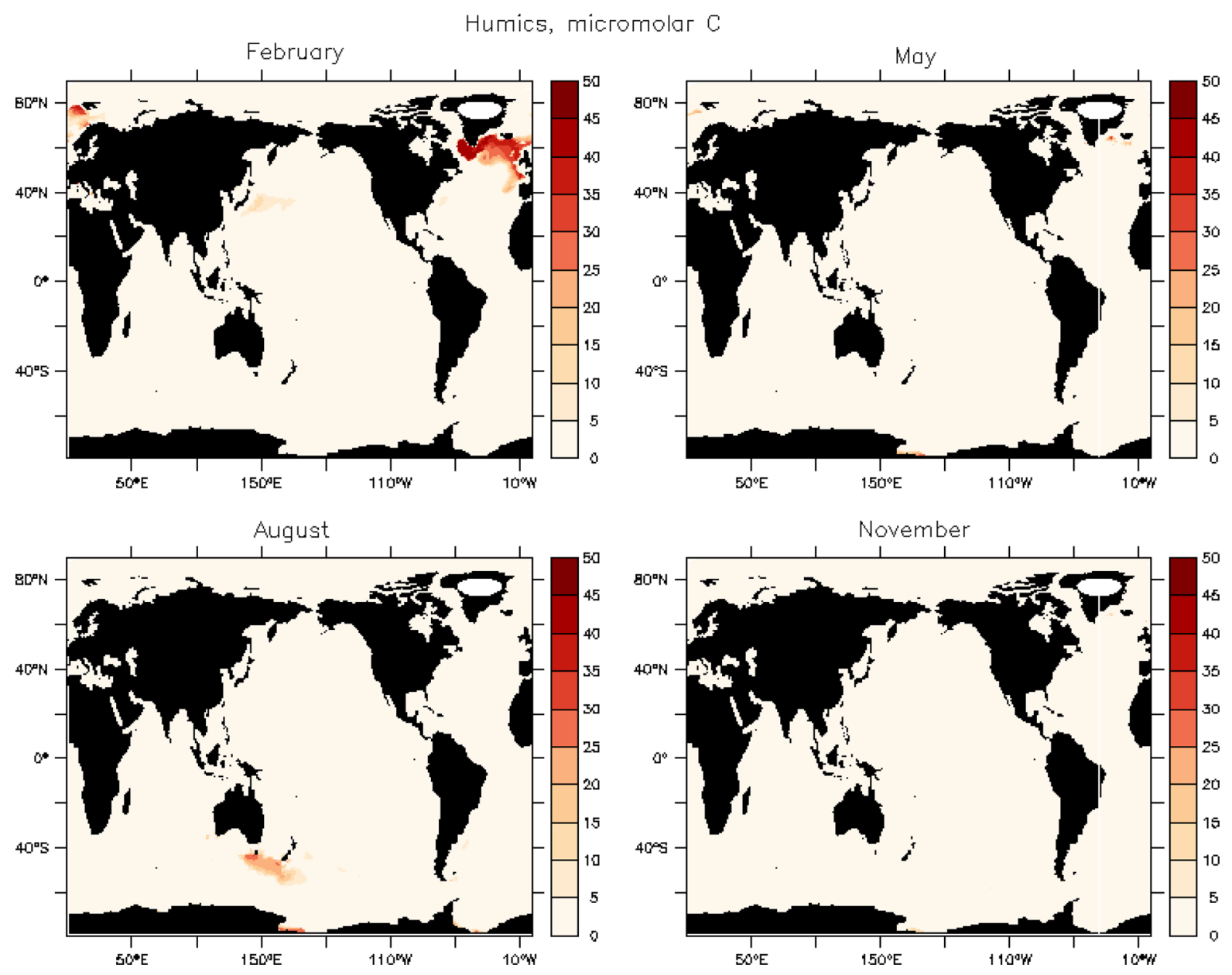

Fig. 6 Global surface ocean humic distributions estimated by our offline mapping procedure, central months of the four seasons. Units are micromolar $(\mu \mathrm{M})$ dissolved carbon

subjected to: freezing, drying, desalination, ultrafiltration, extraction, and acidification. In some instances multiples steps from this list are interwoven into intricate laboratory procedures. The concentration information may only be deducible indirectly, from chemical behaviors recorded at various experimental stages. Polymers may be partially or almost entirely hydrolyzed, reduced or oxidized and organic derivitization is often required to achieve spectroscopic detectability. Rough analytical treatment can cause the breakup of combined heterogeneous forms to yield fragments which are artifacts, amphiphiles or both (Borch and Kirchman 1997; Witter and Luther 2002; Aluwihare et al. 2005; Van Mooy and Fredricks 2010). Still, the level of agreement among diverse methods in the table indicates a certain amount of fidelity.
Recently introduced and improved techniques can be down-selected without changing our overall conclusions (e.g. Kaiser and Benner 2009; Goldberg et al. 2009, 2011). A closer examination of the links between experiment, structure and surface activity is definitely warranted. For the moment, however, we take the conservative standpoint that the tabulated data serve at the very least as a strong guide to organic functionality.

In order to support a relatively complete comparison, we identified measurements spanning the entire historical period discussed in the background section at the top of the text (Lee and Bada 1977 to Goldberg et al. 2011). Collected data are ordered by increasing global average concentration, so that the progression is regular and a quick evaluation of model fidelity is 
Table 3 Comparison of simulated mixed layer concentrations with selected, chemically resolved data for the marine macromolecules
Case studies are listed roughly in order of increasing measured levels, as an aid to the eye. Sites are classified according to the Longhurst ecogeographical system, with abbreviations defined in the text. Concentrations are given in units of micromolar $(\mu \mathrm{M})$ carbon

\begin{tabular}{|c|c|c|c|c|c|}
\hline Class & Province & Season & Model & Data & References \\
\hline \multirow[t]{4}{*}{ Peptidoglycan } & BPLR & Summer & 0.7 & 0.2 & Benner and Kaiser (2003) \\
\hline & PEQD & (Equatorial) & 0.3 & 0.3 & Benner and Kaiser (2003) \\
\hline & NAST & Spring & 0.3 & 0.3 & Kaiser and Benner (2009) \\
\hline & NPTG & Fall & 0.2 & 0.4 & Kaiser and Benner (2009) \\
\hline \multirow[t]{6}{*}{ Lipids } & NPTG & Summer & 0.003 & 0.003 & Loh et al. (2008) \\
\hline & PEQD & (Equatorial) & 0.03 & $0.1-3$ & Gagosian et al. (1982) \\
\hline & NAST & Spring & 0.01 & 0.3 & Marty et al. (1979) \\
\hline & NECS & Spring & $0.1-0.3$ & $0.3-3$ & Kattner et al. (1983) \\
\hline & NWCS & Summer & 0.01 & $1-5$ & Parrish et al. (1992) \\
\hline & NWCS & Spring & 0.03 & 3 & Delmas et al. (1984) \\
\hline \multirow[t]{7}{*}{ Proteins } & GFST & Spring & 3 & $0.3-3$ & Kuznetsova et al. (2004) \\
\hline & NAST & Winter & 1 & 0.5 & Lee and Bada (1977) \\
\hline & PEQD & (Equatorial) & 3 & $0.5-1$ & Lee and Bada (1977) \\
\hline & NAST & Spring & 4 & $0.8-1$ & Kaiser and Benner (2009) \\
\hline & BPLR & Summer & 3 & $1-2$ & Dittmar et al. (2001) \\
\hline & NPTG & (Tropical) & $3-5$ & $1-2$ & Aluwihare et al. (2005) \\
\hline & NPTG & Fall & 5 & $1-2$ & Kaiser and Benner (2009) \\
\hline \multirow[t]{13}{*}{ Polysaccharides } & NAST & Annual & $1-10$ & $2-5$ & Goldberg et al. (2009) \\
\hline & SPSG & Summer & $5-10$ & 3 & Goldberg et al. 2011) \\
\hline & PEQD & (Equatorial) & 10 & 3 & Borch and Kirchman (1997) \\
\hline & NAST & Spring & 5 & $3-5$ & Kaiser and Benner (2009) \\
\hline & NPTG & Fall & 8 & $3-5$ & Kaiser and Benner (2009) \\
\hline & SARC & Winter & 3 & $5-10$ & Mykelstad et al. (1997) \\
\hline & APLR & Summer & 5 & 8 & Mykelstad et al. (1997) \\
\hline & NAST & Spring & $5-10$ & $8-10$ & Witter and Luther (2002) \\
\hline & NAST & Spring & $5-10$ & $8-10$ & Witter and Luther (2002) \\
\hline & APLR & Summer & 10 & $10-20$ & Pakulski and Benner (1994) \\
\hline & SARC & Summer & 10 & $10-25$ & Mykelstad et al. (1997) \\
\hline & NWCS & Spring & 10 & 20 & Aluwihare et al. (1997) \\
\hline & MONS & Winter & 10 & 30 & Bhosle et al. (1998) \\
\hline \multirow[t]{3}{*}{ Heteropoly } & SPSG & Fall & 50 & 60 & McCarthy et al. (1998) \\
\hline & NAST & Annual & $55-60$ & $60-70$ & Goldberg et al. (2009) \\
\hline & NPTG & Fall & 55 & $60-80$ & Kaiser and Benner (2009) \\
\hline
\end{tabular}

possible. Thus the compound order shown in Tables 1 and 2, which is based on ecodynamic mass flow considerations (Parsons et al. 1984; Benner 2002), is approximately reversed. Observations are presented beginning with peptidoglycan then moving toward the high concentration mixed refractories. Locations are specified using the Longhurst biogeographic province system (Longhurst 1998). The lettered sets of interest here are APLR (the Austral Polar province along the periphery of the Antarctic continent), BPLR (Atlantic Boreal Polar, covering much of the Arctic Ocean along with the east coast of Greenland), GFST (the
Gulf Stream), MONS ((Monsoonal regime of the Indian Ocean), NAST (North Atlantic Subtropical gyre, the western half of which is almost synonymous with the Sargasso Sea), NECS (Northeast Atlantic Coastal Shelves but corresponding closely with the North Sea), NPTG (the vast North Pacific Tropical Gyre, but the majority of points were obtained in the vicinity of the Hawaiian Islands), NWCS (the Northwest Atlantic Coastal Shelves province, which is highly biologically active and includes the Canadian Maritimes), PEQD (the Pacific Equatorial Divergence extending from the Galapagos westward to about the 
dateline), SARC (the Atlantic Subarctic zone encompassing Britain, Scandinavia and the Barents Sea), and finally SPSG (the South Pacific Subtropical Gyre transected by cruises in several cases but with key samples collected near the Humboldt Current). Note that the distribution of ecogeography is skewed heavily toward the Northern Hemisphere, as might be expected for a difficult and evolving set of ambient analytical chemical measurements.

Concentrations for open water observations of prokaryotic structural material appear at the top of Table 3. They seem quite realistic. Peptidoglycan and its oligomeric decay products are produced ubiquitously (Benner and Kaiser 2003; Nagata et al. 2003), so they are expected to maintain a fairly uniform global distribution. Overpredictions in the high Arctic are likely traceable to a general ice domain productivity bias, as discussed in the results section just above. Quoted measurements actually represent the sum of hydrolysable, monomeric amino sugar constituents in many cases. Thus a certain amount of the original environmental material may have gone undetected. Here, we incorporate only the heterotrophic source for peptidoglycan. Photosynthetic bacteria will surely add to the concentrations. Our mapped estimates of this prokaryotic byproduct may therefore constitute underestimates at several levels. But the mechanism entails sufficient flexibility that it can be adjusted as necessary in the future.

With the exception of a single comparison for the North Pacific (Loh et al. 2008), baseline lipid concentrations are consistently low by an order of magnitude or more relative to the data sets summarized in Table 3. Here it seems likely that the chosen observations represent overestimates. A few concentration values are available from aerosol-oriented studies conducted in less productive tropical waters, for a variety of fatty acid chain lengths (Marty et al. 1979; Gagosian et al. 1982). But some of these levels are actually calculated indirectly based on remote air samples rather than seawater determinations. For example, a local ocean-to-atmosphere emission model was developed to budget the carbonaceous aerosol at isolated Enewetak Atoll (Gagosian et al. 1982). Overall the spread in observed oceanic lipid concentrations is exceptionally broad. The Canadian maritime biogeochemical province, represented in multiple cases by $\mu \mathrm{M}$ of the lipids or more, actually spans heterogeneous coastal, slope, and open water regimes. The cited investigations average data collected in shore or else over the continental shelf (Delmas et al. 1984; Parrish et al. 1992). Hence they probably reflect enhanced primary production.

Starting with the proteins our offline mapping procedure begins to overestimate the molar concentrations relative to available data. However, the baseline scheme for this particular organic class involves only a zeroth order weighting of semi-labile and shorter lived macromolecular distributions. In future work, we plan to conduct dynamic simulations online, inside of ocean circulation coding. The polysaccharide concentrations compare reasonably well to observations except at the highest concentrations, but this in fact is where the analytical chemistry is at its most challenging. A mix of total carbohydrates and neutral sugars is actually represented, as discriminated by hydrolytic, spectroscopic derivative, redox and chromatographic techniques of variable internal reproducibility. Our mixed polymeric material concentrations also agree well with observations. But since this field is generated approximately by working backward from different sorts of refractory carbon climatology, the outcome is expected. Problems should be anticipated for all carbohydrate material in high productivity coastal waters and inland seas, since they are currently under sampled and difficult to model. Indonesia and the Humboldt Current offer prominent examples but no data sets appear to be available.

Measurements for the individual macromolecules are regionally sparse, but collected at the global scale they are nonetheless sufficient for a preliminary statistical analysis. A nonparametric approach is presented as a series of box diagrams in Fig. 7. Selected observations extracted from the range of Table 3 studies are visualized in a quartile format. Dissolved concentrations are separated into low and high carbon subsets since the spread among compounds is broad. Outliers are separated by whiskers and depicted explicitly where they become relevant. All conclusions drawn from our biogeographic arguments are confirmed in the figure. Simulated peptidoglycan concentrations constitute slight overpredictions, but the analytical chemistry certainly leaves room for average measured concentrations to rise. Lipid simulations fall below the interquartile range of available data, but some major studies are biased coastally. The global protein discrepancy is small and readily adjustable since in this case our modeling really constitutes a weighting procedure. Sugar calculations are reasonable excluding a few extremes which 


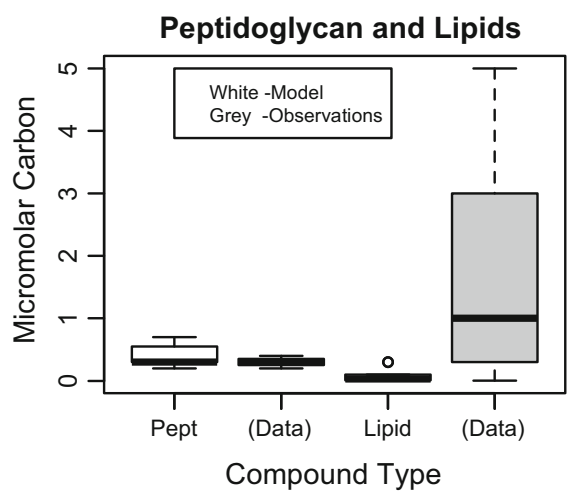

Fig. 7 Global box plot comparisons of modeled versus measured concentration, for a selection of data from the references of Table 3. Central quartiles and outlier boundaries are provided so that dispersion and skewness of the underlying

may again be attributable to complexities of the experiments. Heteropolycondensate values are in the dozens of micromolar but show relative agreement, as expected from our heavily data-driven approach. In several important cases in the plots of 7, estimated and observed bars overlap, lending confidence to the details of our method. Only the lipid discrepancy is large and it may well reflect skewed sampling.

Overall, it can be concluded from Table 3 and Fig. 7 that our mapping procedure achieves a reasonable level of fidelity relative to the dissolved organic carbon measurement literature. All the major compounds under consideration are represented in a simple offline fashion to within an order of magnitude of their empirical concentrations, wherever convenient data are at hand for evaluation. The lipids are a possible exception but this may be due primarily to coastal offsets. A combination of dynamic computation with enhanced observation and interpretation is likely to reduce the gap. We infer that the marine organic chemical simulations developed in the present work are of sufficient quality that we can now move forward, to an exploration of global scale Langmuir adsorption. This is accomplished by combining information in the tables and figures as they have been presented so far, according to logic laid out in the methods section.

\section{Results: surface activity}

Surfactant kinetics are often considered to be rapid relative to timescales for bubble transport through the

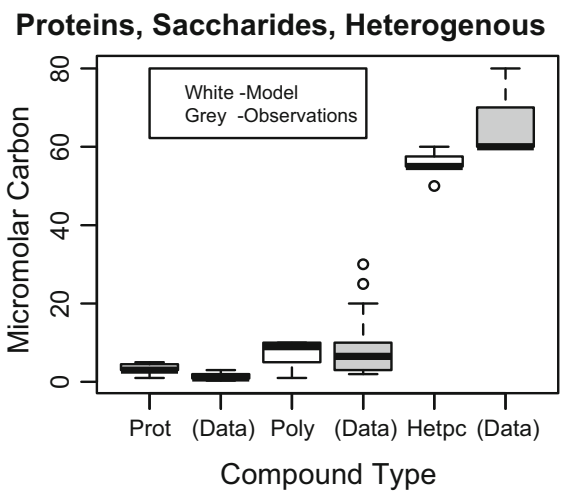

distributions are apparent in a nonparametric sense. Abbreviations: Pept -peptidoglycan. Prot -proteins. Poly - polysaccharides. Hetpc see Table 1

upper mixed layer. This has partly been a matter of convenience, but the conclusion is consistent with a large body of laboratory evidence. Even in small tank experiments implying short and artificial trajectories, surface saturation is often demonstrable (Hoffman and Duce 1976; Blanchard 1989). In a recent study of interfacial buildup by the marine organics, Fuentes et al. (2010) obtained equilibration times much faster than bubble return to the atmosphere. The molecules under study consisted of typical phytoplanktonic exudates. The authors offer a Gibbs-Langmuir-Szyszkowski based analysis of the process, incorporating realistic macromolecular diffusion rates and bubble boundary layer theory. They conclude that for typical marine situations, full surface coverage is achieved in milliseconds. In fact the researchers go so far as to state that it is effectively instantaneous.

There are undoubtedly circumstances in the global regime under which restricted bubble penetration and slow polymer diffusion rates lead to significant undersaturation. But for the moment and in common with many preceding groups, we assume standard Langmuir equilibrium as a startup expedient. Coverage and carbon mass are then readily calculated from the relationships in 17. In Figs. 8 and 9 we couple the mixed layer distributions presented earlier with settings compiled in Table 2. Normalized concentrations $K_{i} C_{i}$ are inserted into the competitive multispecies isotherm yielding coverage and excess for individual components $k$. Surfactant contributions to the global monolayer are then distributed across the surface ocean based on our parameterized biogeochemistry. 
Air-Water Coverage in February, log dimensionless
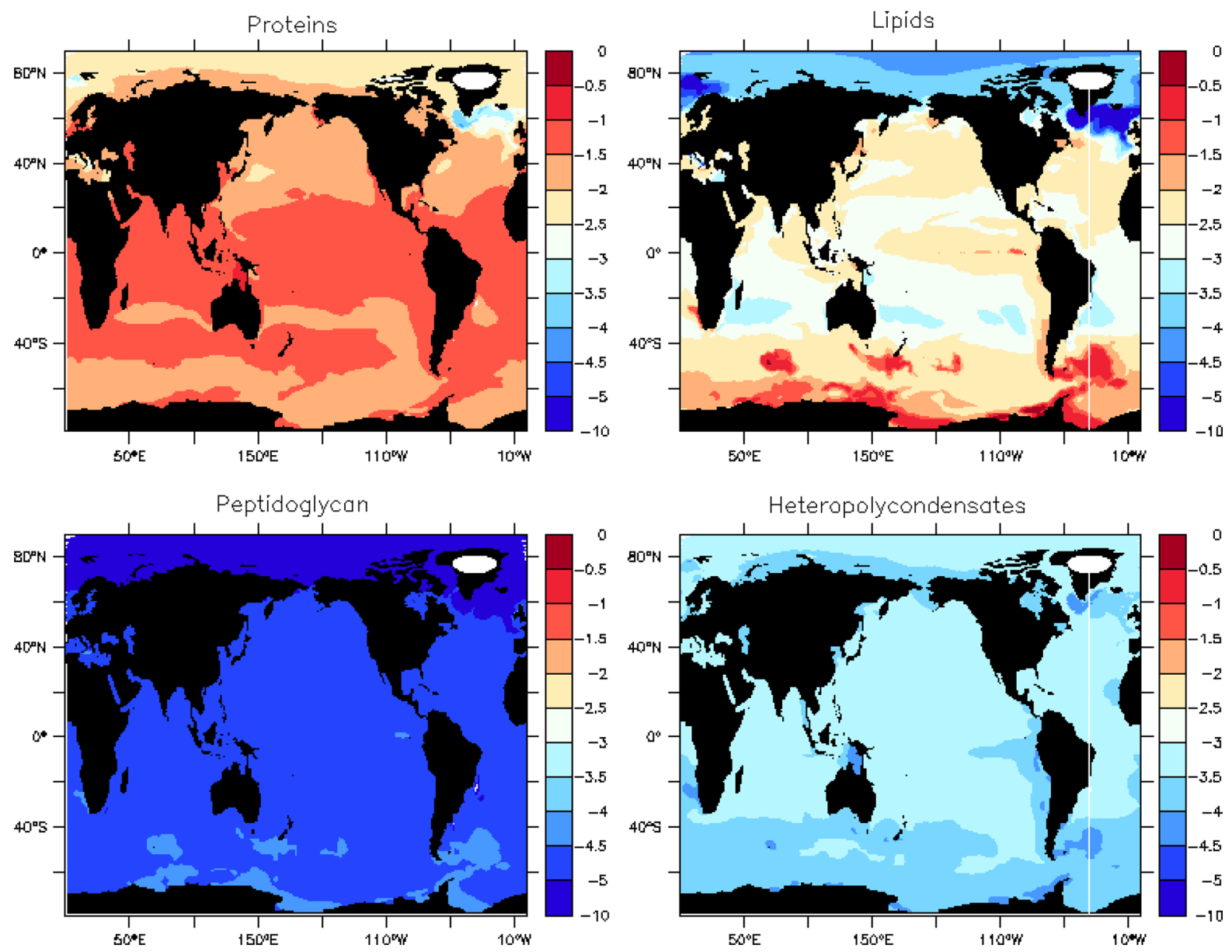

Fig. 8 Fractional Langmuir coverage of air-water interfaces in the upper ocean, for a baseline run defined by Table 2 . Only the February result is shown, but other seasons follow annual trends

From the fractional surface coverage and the maximum areal concentration of each species we compute the actual excess, i.e., an estimate of carbon burden per unit interfacial area of the bubble or microlayer. For convenience in comparison with film and aerosol salt content, the unit of choice is now moles $/ \mathrm{m}^{2}$.

Surfactant mass is readily interpretable in the context of ocean interfacial chemistry through a series of orientation calculations. First of all, we convert the lower limit excess data of Table 2 from the microscopically intuitive value one per square angstrom to an equivalent level of $2 \times 10^{-4} \mathrm{~mol}$ carbon $/ \mathrm{m}^{2}$. This facilitates a calculation of critical "column" concentrations, provided for comparison with the amount of salt in a bursting bubble film. Rising bubbles may from 1 through 6 . The quantity is dimensionless and is presented as the base 10 logarithm

acquire additional organic layers during their transition through the ocean-atmosphere interface (Elliott et al. 2014; Burrows et al. 2014). It is clear from Table 2 data that maximum excess is a strong function of molecular structure. Values are often many times greater than a single $\mathrm{C}$ per bond length. Complex stacking configurations are regularly reported in experimental studies (e.g. Graham and Phillips 1979; Shogren and Biresaw 2007; Damodaran and Razumovsky 2003; Babak et al. 2000). Therefore we adopt the round figure spread $1-100 \times 10^{-4} \mathrm{~mol} / \mathrm{m}^{2}$ as a reference range. Potential carbon densities for the marine macromolecules are completely bracketed in two dimensions, under conditions of full or maximum surface coverage. 
Carbon Excess in February, log of mole per square meter
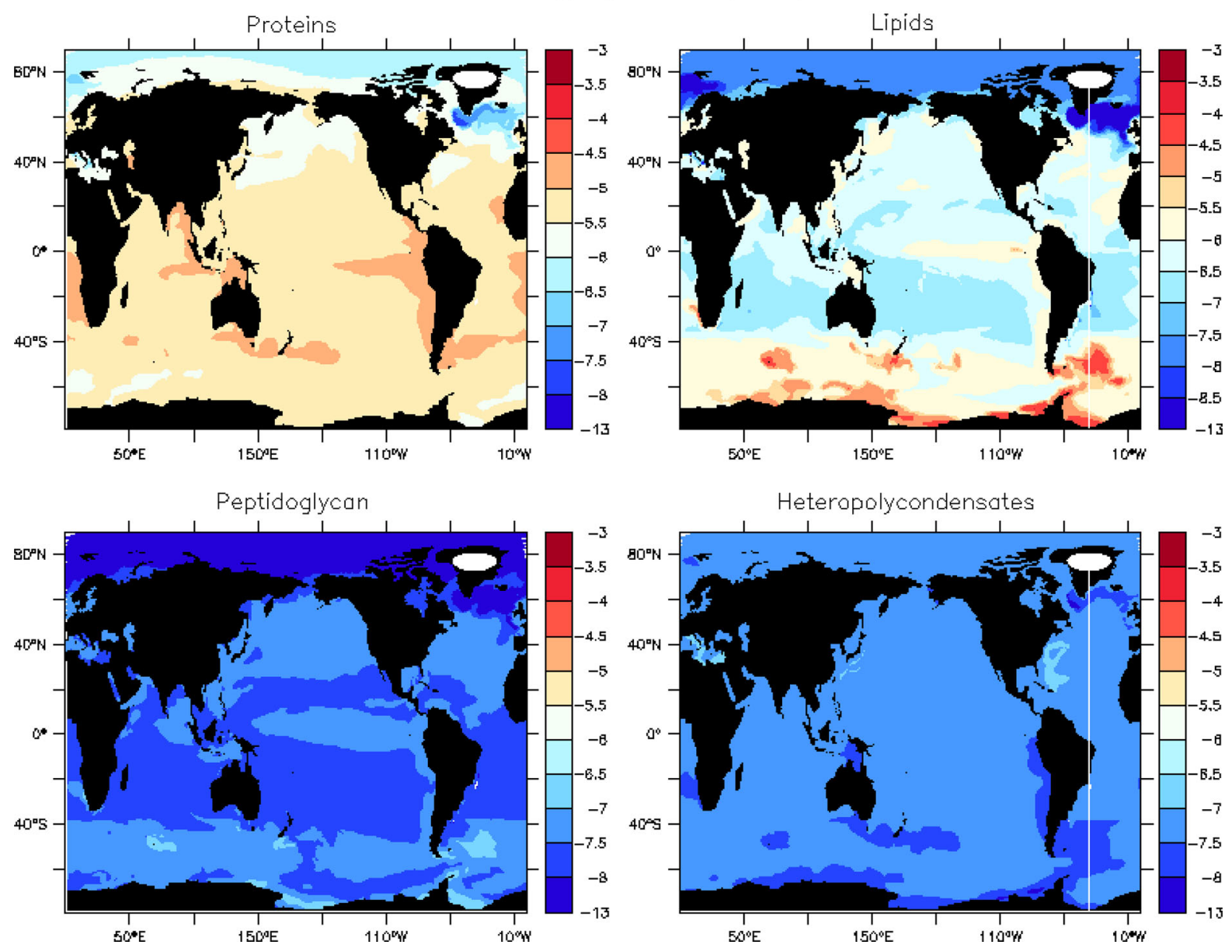

Fig. 9 Carbon mass excess on air-water interfaces of the upper ocean, for a baseline run defined by Table 2. Only the February result is shown, but other seasons follow annual trends from 1 through 6 . Units are moles $/ \mathrm{m}^{2}$ but the color bar is logarithmic

Breaking bubbles and the nascent spray are thought to be similar in thickness at about one-tenth micron (Gong 2003; O’Dowd and De Leeuw 2007; Modini et al. 2013; Burrows et al. 2014). The spectrum of sea spray flux peaks near this value, so the original film may be thinner-surface tension reshaping follows closely upon bursting once the material enters the atmosphere. The average salinity of the ocean is about $35 \mathrm{psu}$, so that the $\mathrm{NaCl}$ concentration can be fixed at 0.5 molar for our purposes (Longhurst 1998). This translates to a reference column salt burden of $5 \times 10^{-5} \mathrm{~mol} / \mathrm{m}^{2}$ over a nominal distance of $10^{-7} \mathrm{~m}$. Thus for saturated airwater interfaces, carbon in the bio-macromolecules would be quite capable of competing on a molar basis with sodium or chloride during transport into the atmospheric boundary layer (Elliott et al. 2014; Burrows et al. 2014). This result is corroborated in many recent marine aerosol measurement studies (O'Dowd et al. 2004; O'Dowd and De Leeuw 2007; Russell et al. 2010; Lapina et al. 2011; Cunliffe et al. 2011). Our goal is to offer more detailed resolution in the chemical oceanographic sense, through the various numerical mapping techniques.

The previous tables and figures already suggest indirectly that two-dimensional surface fractions may be large over much of the global ocean. For example, compare protein and lipid maxima with their respective half saturations in Table 2 (converting molar equilibria to $\mu \mathrm{M}$ ). Normalization of these concentrations as in $\mathrm{C} / C_{1 / 2}$ (Eq. 13) gives a quick indication of the approach to unit coverage in a Langmuir monolayer (Adamson 1960; Adamson and Gast 1997; Elliott 
et al. 2014). Since both ambient levels and half saturation values are in the vicinity of $\mu \mathrm{M}$, large proportions are plausible. To demonstrate this visually and geographically, we present the standard Langmuir theta parameter (fractional coverage) as calculated for the three most adsorptive carbon classes (proteins, lipids, peptidoglycan) and also for the massive reservoir of mixed polymers (heteropolycondensates). Global distributions are shown for this suite of compounds in Fig. 8, for the month of February. In the other months/ seasons patterns merely progress according to the solar cycle as shown in the plots of 1-6. Competitive multispecies coverage in the monolayer is expressed as a base 10 logarithm in order to accommodate the wide range which must be simulated.

Figure 8 is taken as a baseline result and major inferences are as follows. In this particular simulation, proteins approach two-dimensional saturation over large sections of the ocean environment, as indicated by light red to red on the log color scale. Lipids also achieve high fractional coverage, but only in regions of intense biological activity. In either case, our reference points regarding film column burden suggest that the enrichment of organics through Langmuir adsorption may well be sufficient to explain their large contribution to the fine-mode aerosol. Protein coverage extends into the central basin gyres, since this class is treated partly as a transportable semi-labile. By contrast the shorter-lived lipids are computed assuming steady state with phytoplanktonic cell disruption, so that they are confined to immediate source regions. Heteropolycondensate coverages tend to surpass those of peptidoglycan. This is despite a lower baseline halfsaturation concentration in the latter case. Hence the dominance of heteropolycondensates is attributable to their much higher concentrations in the ocean, resulting from the well-known accumulation of refractory carbon at middle latitudes (Fig. 5; Benner 2002; Hansell et al. 2012).

Carbon excess or absolute two-dimensional concentration is summarized for the Northern Hemispheric winter period in Fig. 9. Values are presented on a log scale and now they can be directly compared with the sodium content of an idealized breaking seawater film: $5 \times 10^{-5} \mathrm{~mol} / \mathrm{m}^{2}$ assuming thickness of 0.1 micron and treating the system as a homogeneous slab. Protein and lipid-derived carbon are again the dominant groups, and they are potentially salt competitive on a carbon-molar basis in areas of strong primary production. The relative ranking of the macromolecular groups remains in the order from Fig. 8, since water column concentration distributions are unaltered and the two dimensional maxima do not differ dramatically. For this baseline simulation, we assigned an intermediate maximum excess of 10 wherever Table 2 data fell in the range 1-100 and 1 wherever the value fell between 1 and 10 atoms per square angstrom (parentheticals in the main table field).

Several authors on this paper are involved in organic functional group analysis of marine aerosol composition. Filter samples have been collected during ship-board experiments, and artificially-generated marine particles were produced by creating bursting bubbles in natural seawater during research cruises (AF, LR). Fourier transform infrared spectroscopy (FTIR) was used to determine amounts of the major bonding structures. A key finding has been that carbon-hydrogen moieties (meaning alkanes) and the hydroxyl (generally in carbohydrate-like structures) are present in roughly equal proportions, whether in clean marine particles or bubbling analogs (Russell et al. 2010; Frossard et al. 2014). Proteins are the dominant surfactant species in our baseline run, but on average they contain only a low ratio of $\mathrm{OH}$ to $\mathrm{CH}$. For example, among the most abundant oceanic amino acids only serine has the hydroxyl attached to its $\mathrm{R}$ substituent (Benner 2002; Parsons et al. 1984). The implication of such comparisons is that additional sources of carbohydrate may be required in the model. For example, the relative adsorption tendency of the polysaccharides may be underestimated in the runs presented so far. Or there may be complementary mechanisms of sea-air transfer involving colloids and gels (Cunliffe et al. 2011; Wurl et al. 2011). In addition to the fresh and conceptually pure polysaccharides of Table 1, both peptidoglycan and the heteropolycondensates are carbohydrate-rich, so that they could play into any alternate mechanisms

Spectroscopic analysis can also be extended beyond alkyl versus hydroxyl to include a wide range of organic functional groups. Amines and amides have been reported in some regions, and these would in fact be consistent with the high protein excess obtained here in our Langmuir scenario (Russell et al. 2010; Frossard et al. 2014). The actual molar ratios of major functional groups in seawater organics are presented in Table 4 as derived from standard analog compound 
Table 4 Selected functional relationships from the ocean macromolecules considered here as potential adsorbing agents

\begin{tabular}{llllll}
\hline Class & Model & CH/C & OH/C & Am/C & References \\
\hline Protein & Average & 0.9 & 0.1 & 0.3 & Benner (2002); Parsons et al. (1984) \\
Polysaccharide & Glucose & 1.0 & 0.5 & & Parsons et al. (1984); Goldberg et al. (2009) \\
Lipid & Stearic acid & 1.9 & & & Brzozowska et al. (2012) \\
Chitin & Pure & 1.0 & 0.25 & 0.125 & Kumar (2000) \\
Peptidoglycan & Peptide arms & 0.94 & 0.15 & 0.21 & Nagata et al. (2003); Parsons et al. (1984) \\
Heteropoly & $95 / 5$ & 1.0 & 0.48 & 0.015 & Benner (2002); Malcolm (1990) \\
\hline
\end{tabular}

Composition is characterized by the molar ratio of each group to total carbon atoms in a given molecular structure. Values in the table are condensed from a data base maintained by the authors. It is referred to as GELOMOLD, for Global Excel Listing Of Marine Organic and Ligand Data

$\mathrm{CH}$ and $\mathrm{OH}$ individual carbon-hydrogen or hydroxyl bonds. Am either amide or amine. 95/5 percentages of carbon present as polysaccharide versus protein in the mixed condensate

structures. Bonds are counted according to the methods of Russell et al. (2010) so that the values are FTIR relevant. It becomes clear that saccharides and mixed polymers must be involved in spray generation in at least some combination. But additionally, amino acids arising from the proteins are implicated as a major source of nitrogen atoms. Lipids provide a likely explanation for $\mathrm{CH}$ (alkane) richness in a given bloom regime, but proteins and amino sugars cannot be excluded as contributors. The situation is complex, but it is probably amenable to a more detailed sourcereceptor type analysis. We believe this could serve as a secondary application of the mapping procedures introduced here.

An overestimation of protein bubble coverage could of course be partially attributable to biases in the underlying concentration distribution (Table 3). But uncertainties in the Langmuir coefficients are much greater (references in Table 2). Thus we will conclude this section with a brief sensitivity study focusing on the half saturation parameter. The reference compound lysozyme that was initially adopted to represent marine protein has a $C_{1 / 2}$ of $10^{-4}$ molar. This particular proxy choice is of course terrestrial, and it was necessitated by a lack of laboratory measurements for ambient marine polymers. Lysozyme is globular, and denaturing should relax the structure of any enzyme released freely into seawater. However, our most important protein reference also contains data for casein (Graham and Phillips 1979). We thus experimented with a smaller half concentration of $10^{-5}$. Continuing the pattern, we also reduced the $C_{1 / 2}$ associated with heteropolycondensate carbon to the level $10^{-2}$, since proteinaceous impurities are likely to enhance adsorptivity (Damodaran and Razumovsky 2003). Results for the sensitivity test phase of our calculations are shown in Figs. 10 and 11, which are patterned after 8 and 9 respectively in terms of compound order and seasonality.

Given the altered half saturations, carbon coverage attributable to the protein source is increased considerably over the entire global ocean. As expected, the heteropolycondensate contribution also increases. This second run naturally moves net surface fractions and masses in the same direction for the protein and processed macromolecular reservoirs. Such changes may bring the model somewhat closer to agreement with the FTIR measurements of artificially-generated marine aerosol particles. The increase in mixed condensate implies a higher relative contribution from $\mathrm{OH}$ over large areas, and especially in the subtropics. Lipids remain locally dominant in Figs. 10 and 11, but their influence is now more tightly confined to productive ring ecosystems of the Southern Ocean (Longhurst 1998). This result is consistent with a correlation of alkyl to ocean chlorophyll, as observed in the spectroscopic analyses of Frossard et al. (2014).

Preliminary sensitivity test results presented in Figs. 10 and 11 touch upon only two of the potential means by which model-data agreement might be improved here. In addition to these cases, a series of simulations was performed in order to explore other mechanisms for increasing the concentration of $\mathrm{OH}$ functional groups toward the observed range. For instance the baseline analog for polysaccharides was replaced with gum arabic in one set of runs 
Air-Whater Coverage in February, log dimensionless
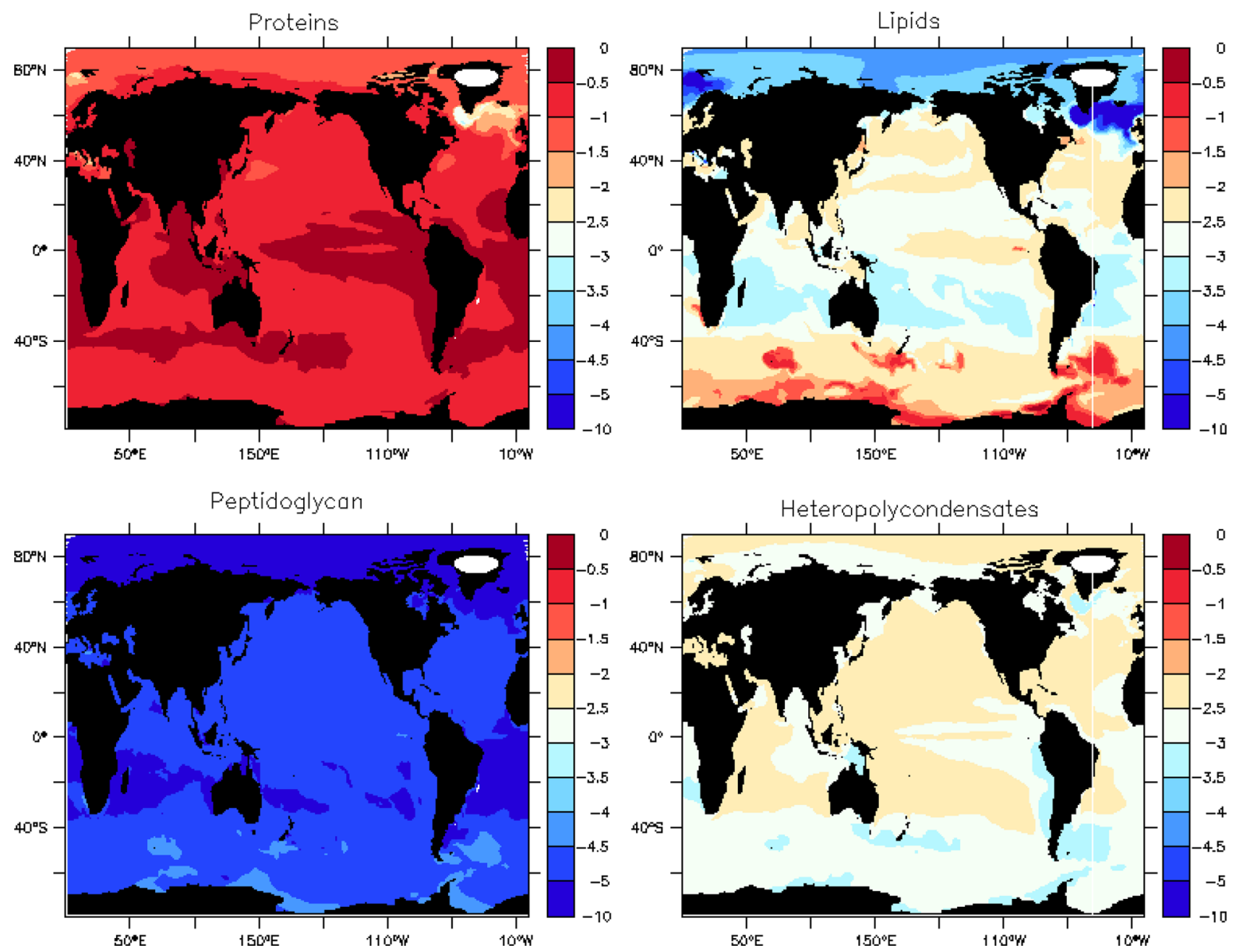

Fig. 10 Fractional Langmuir coverage of air-water interfaces in the upper ocean, sensitivity test with half saturations decreased 10x for proteins and the heterogeneous polymers.

(Damodaran and Razumovsky 2003). The half saturation concentration for this well-known food additive is about an order of magnitude less than that of alginate. In another test, the equilibrium constant for peptidoglycan was reduced by a factor of ten. We also represented the high latitude humics as amphiphiles, giving them a $C_{1 / 2}$ of $10^{-5}$ in several different computations. All these alternative scenarios provide possible ways of increasing the hydroxyl in marine aerosols.

True polymeric surfactants will behave in a nonideal manner, with surface coverage as a function of aqueous concentration deviating significantly from Langmuir adsorption. The irregularities may result from subtleties of the two dimensional packing

Only the February result is shown, but other seasons follow annual trends from 1 through 6 . The quantity is dimensionless and is presented as the base 10 logarithm

structure, or else conformation changes as film pressure increases. Under these circumstances the excess maximum becomes a variable quantity (e.g. Graham and Phillips 1979). Moreover, the macromolecules under consideration are often incorporated into larger colloidal particles in the surface ocean. These in turn may be efficiently collected by pure mechanical impaction on rising bubbles. Additionally, some marine particulates are capable of rising gradually to the surface due to their own buoyancy (Cunliffe et al. 2011). Polymers and gels will interact across the marine size spectrum, opening a variety of multiphase transport pathways (Wells 2002). Our view is that the classic Langmuir approach to surface activity allows for construction of a semi-quantitative 


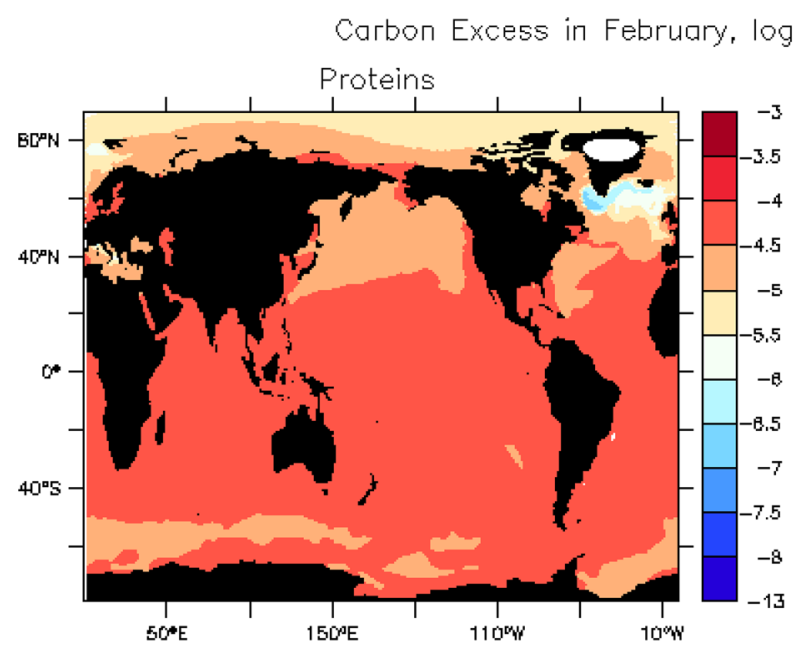

Carbon Excess in February, log of mole per square meter
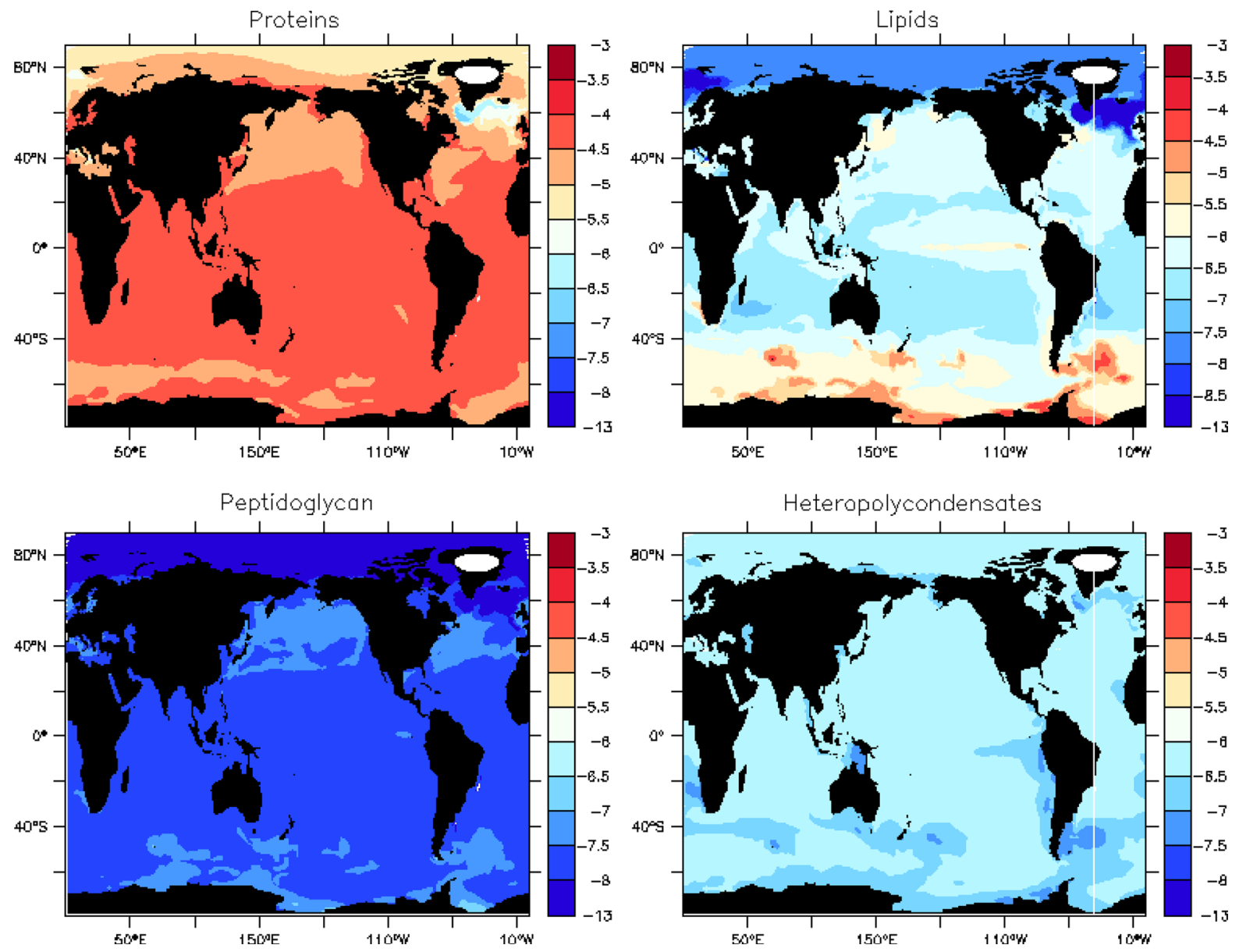

Fig. 11 Carbon mass excess on air-water interfaces of the upper ocean, sensitivity test with half saturations decreased $10 \mathrm{x}$ for proteins and the heterogeneous polymers. Only the February

but conceptually powerful foundation, from which these other issues may be discussed and investigated.

\section{Summary and discussion}

The sea-air transfer of marine macromolecules influences background aerosol composition over the majority of the planetary surface (O'Dowd et al. 2004; Russell et al. 2010; Cunliffe et al. 2011; Lapina et al. 2011). Uncertainties in biogenic emissions propagate into the chemistry of nascent spray, and could ultimately impact global climate through $\mathrm{CCN}$ fields operating on cloud albedo (Meskhidze et al. 2011; Carslaw et al. 2013). Effects may be felt on

result is shown, but other seasons follow annual trends from 1 through 6 . Units are moles $/ \mathrm{m}^{2}$ but the color bar is logarithmic

atmospheric particle size, hygroscopicity, vapor uptake and reactivity. Phytoplanktonic ecodynamics are widely considered to be a major driver of primary organic aerosol sources (O'Dowd et al. 2004; Meskhidze et al. 2011; Gantt et al. 2011). Chlorophyll-a correlation methods have often been invoked initially in order to represent organic distributions in the water column. In the present work we explore an option based on more complete biogeochemistry. Dynamics of the source macromolecules are represented at the level of internal mixed layer processing across the entire surface ocean. Concentration distributions are estimated for a chemically resolved set of long-chain organics and polymers. The patterns analyzed are constructed for the organic compounds 
through offline mapping techniques, using both steady state and proxy tracer methods as needed (Eqs. 1-3; Table 1; Figs. 1, 2, 3, 4, 5, 6).

Since sea spray is generated through bubble breaking at the surface, the suite of marine macromolecules is treated as a collection of ideal isothermal Langmuir adsorbers (Eqs. 13-17). Surfactant equilibrium parameters are derived from appropriate laboratory studies, and assessed for their significance in the open ocean context (Table 2; Figs. 8, 9, 10, 11). Fractional coverage of the air-water interface is estimated as a competitive, multispecies process for the entire global ocean-atmosphere interfacial system. The surface fractions are then converted into densities expressed as the carbon excess, a measure of the areal organic burden. This value is compared with the mass of salt contained in idealized bubble films and thus also in the sea spray aerosol. The polymer and surfactant chemistry relationships involved have been discussed in the literature over a period of several decades (e.g. Liss 1975; Liss et al. 1997; review sections in Elliott et al. 2014 or Burrows et al. 2014). Our main contribution in the present work is to apply modern Earth System model output and mapping tools to the problem (Gregg et al. 2003; Moore et al. 2004; Elliott 2009; Elliott et al. 2011). We develop estimates for the biogeographic distributions of multiple organic classes based on a state-of-the-art marine ecodynamics package. Relative mass contributions are then computed for surfactant films forming at the global air-water interface. Results may be taken as chemically and biogeographically resolved indicators of input to the organic portion of the nascent aerosol.

Our primary motivation in this research is to identify regional variations in ocean carbon composition which may transfer to the atmosphere. A Langmuir mechanism is adapted to this task because it constitutes a reasonable and tractable starting point. We begin by identifying six classes of high molecular weight organic compounds for simulation: aggregated proteins, polysaccharides, and lipids along with the rigid structural polymer chitin, prokaryotic cell wall derivatives such as peptidoglycan and its oligomeric decay products, the dominant highly processed refractories of the central gyres, and finally, deep water humic acid (Table 1). In the offline maps, protein, polysaccharide and heteropolycondensate reservoirs accumulate concentrations of tens $\mu \mathrm{M}$ carbon in the open surface sea, but regional distinctions are significant. By contrast, the lipids and peptidoglycan maximize in zones of high biological activity because they are relatively labile, and peaks are only of order $\mu \mathrm{M}$. Peptidoglycan contours extend into the central gyres because this molecule is produced in our representation by the heterotrophic bacteria. Mixed polymers are computed from the difference between climatological refractory DOC and the remaining surface organic molecules, but it is clear that they accumulate at middle latitudes. We assume humics are transported upward from deeper ocean layers, and this occurs exclusively during deep winter convection.

In addition to simulating distributions of the macromolecules, we also estimate both fractional surfactant coverages and surface excess (two dimensional) concentrations for each class of compound. Results should be applicable to a variety of air-water interfaces in the mixed layer, e.g. both the internal surfaces of wave-generated bubbles and the oceanatmosphere interfacial microlayer (Russell et al. 2010; Cunliffe et al. 2011). Our Langmuir chemical calculations are presented only for the month of February, since the effects of seasonal cycling are readily apparent from annual mass distributions. In a baseline model configuration, proteins are globally dominant and they appear capable of saturating upper ocean surfaces over some of biogeographic space and time. This is due to a combination of high concentrations and the laboratory adsorptivity, but of course both quantities are moderately uncertain. The lipids are strongly hydrophobic and they too can support near unit coverage, but influence is limited to areas of high primary productivity. These extend along subtropical and subpolar fronts, eastern basin upwellings, the equator, and even into the winter hemisphere in some ecological provinces. Peptidoglycan remains greatly undersaturated in the sense of surface activity in our baseline run, since both concentrations and the adsorptive tendency are intermediate. Mixed refractory products are competitive with lipids in the central basins where their relative concentrations are greatest. The baseline calculations take into account nonideal monolayer configurations for aminosugar and polysaccharide structures, reflecting the potential for balling and clumping of their carbohydrate chains (Damodaran and Razumovsky 2003; Shogren and Biresaw 2007).

The Langmuir parameters adopted here are mainly estimated based on the behavior of analog compounds in the laboratory (Table 2). Both equilibrium half- 
saturation levels and the maximum excess carbon concentration are highly uncertain when applied as global averages. Indications are that real values could differ by an order of magnitude or more. A primary sensitivity test was therefore conducted, focusing on our estimates of the adsorption equilibrium constants (Eqs. 13 and 17). In a set of simulations moving beyond the baseline, a direct relationship was demonstrated for the half saturation concentrations with fractional coverage. New choices of adsorptive proxy species increased the regional dominance of proteins and the proportion of carbohydrate in our simulated coatings. We were thus able to raise the profile of saccharide hydroxyl functionalities in the blend of molecular structures lining air-water surfaces. We show that this brings the modeled-mapped results closer to experimental values, obtained during shipbased aerosol/bubble sampling with spectroscopic detection (Russell et al. 2010; Frossard et al. 2014).

The runs described here were performed entirely offline in the computational sense, by importing results from a well-established marine systems model into a convenient analysis and graphics package (Moore et al. 2004; NOAA Ferret). Steady state kinetics or approximate distributions are implied for all tracers involved. It is likely that results will vary somewhat when the opportunity arises to repeat our research in the context of real chemical transport dynamics. In more complete calculations, we intend to include a broader variety of model compounds including lipoproteins, lipopolysaccharides, phosphorylated organics, plus intermediate and mixed oligomers (Parsons et al. 1984; Benner 2002). Statistical approaches may then be required to organize an increasing number of conversion rate and surfactant parameter estimates. We are aware that the equilibria lying at the core of the approach are very much approximate. In many cases data were selected and interpreted from room temperature, low ionic strength laboratory studies. Salt concentrations approach unit molarity across the global surface ocean, and polar temperatures drop well below the freezing point of pure water (Parsons et al. 1984; Longhurst 1998). Thermochemical adjustments are thus called for, in order to incorporate realistic temperature and salt effects. The Langmuir model assumes idealized surfactant behaviors such as a fixed maximum excess, and the absence of chemical interactions in two dimensions (Adamson 1960; Somorjai 1972; Adamson and Gast 1997). Actual surfactants display reconfigurations, which may dramatically alter the holding capacity of a phase boundary. Two-dimensional acid base relationships and reactive chemistry can also occur along aqueous interfaces (Kanicky and Shah 2002). Electrostatic interactions may enhance the effective thickness of the adsorbed material (Parra-Barraza et al. 2005). At least some of these challenges may be susceptible in the near term to a careful blend of theoretical and laboratory investigations. Detailed extensions of our work may prove crucial in extreme environments such as polar and ice (brine) biogeochemical systems.

The discussion as presented thus far necessarily involves a lengthy catalog of uncertainties, and so perhaps it is useful to recap at this stage. Errors in our approach may derive from several sources, and all are reflected in the parameters underlying a macromolecular chemistry-transport-surfactant formulation (equations plus Tables 1 and 2). Although global organics may prove critical to comprehension of the marine aerosol (O'Dowd et al. 2004; Russell et al. 2010), processes controlling their distribution and behavior remain very poorly known. Injection schemes, carbon proportions and removal rates adopted preliminarily here are all highly idealized (Parsons et al. 1984; Hansell et al. 2012; Table 1). Biomass fractions are represented as globally averaged carbon percentages rounded in the tens place. Mechanisms are streamlined and lifetimes are merely best estimates to the nearest power of ten in units of days. Physical chemistry is simulated via simple polymers which are often missing organic functionalities or combinations thereof. Higher fidelity representatives should be sought, from among biomacromolecular permutations which are nearly endless. Thus the list of tabled compounds will become steadily longer, though of course complexity of the real marine environment can never be approached. Even fundamental dependencies of the core chemical equilibria on temperature or salinity have been subverted for the moment (Adamson 1960; Somorjai 1972; Graham and Phillips 1979; Elliott et al. 2014).

And although we may have succeeded in mapping certain prominent bonding structures to within an order of magnitude (Table 3 and Fig. 7), error bars are much greater for their surfactant properties including coverage and excess (Table 2). This conclusion can be drawn from our own survey of the surface chemical literature, with order of magnitude biases likely in many cases (e.g. contrast the protein classes of 
Graham and Phillips 1979). Langmuir coverage and carbon mass per area lie at the heart of our arguments, and so it might be concluded that the fundamental logic itself is uncertain. But by the same token our conceptual/theoretical grounding is firm, whether viewed from the standpoint of marine organic chemistry or surfactant physics (Liss 1975; Adamson and Gast 1997; Liss et al. 1997; Benner 2002; Elliott et al. 2014). Hence the arguments and results merit at least initial consideration. All of our statements regarding potential biases can clearly be qualified -this particular systems-level distribution and mapping exercise is the first of its kind, so that further research will definitely improve the situation.

Perhaps the most important discrepancy in our research is revealed by comparison with the organic functional groups identified in spectroscopic data (Russell et al. 2010; Frossard et al. 2014). FTIR analyses of atmospheric marine aerosol particles, artificially generated analogs, and seawater organic matter all indicate that carbohydrates with the expected large fractions of hydroxyl functionality must be prominent components. While there is also evidence for the presence of organic nitrogen in the marine atmosphere (Mopper and Zika 1987; Russell et al. 2010), the majority of material seems to be saccharidic in nature. We begin to approach this result by optimizing the chosen equilibrium values, but other resolutions are possible as well. It is conceivable that polysaccharides form small particles in the water column which are simply swept to the level of the microlayer and above via bubble impaction (Wells 2002; Wurl et al. 2011). Carbohydrate structures are known gelling agents and in fact have a buoyant rising component of their own, associated with low internal density (Cunliffe et al. 2011). The inability of our preferred, baseline parameter set to completely explain observed functional breakdowns is unsurprising. It may merely demonstrate that higher fidelity half-concentrations need to be incorporated. But it is also likely that mechanical lifting of the polymer field must be parameterized, or that multiple layer effects need to be incorporated. A portion of the dissolved polysaccharide is acidic (Hung et al. 2001), so that the abundant divalent cations of seawater may act as bridging ions to attach the sugars as cooperative layers. In future computations, numerical connections could be made with the rising bubble field, buoyant particle types and multilevel isotherms to augment vertical transport through the water column.
These and other additional topics will be investigated in second-generation simulations already underway in our group. We are currently planning for the direct coupling of organic chemistry into the ocean circulation components of generalized Earth System Models. The goal will be to provide realistic sources of biogenic aerosol that are simultaneously dynamic and responsive to climate feedbacks. The concentration fields we describe will likely shift significantly in the era of global warming -as the ocean stratifies, as areas of primary production shift poleward, and as growing seasons lengthen toward the poles. We are hopeful in the meantime that mapped estimates of macromolecular distributions will prove useful to the contemporary aerosol community as a research guide. A sense of regional and global availability is afforded for chemically resolved ocean carbon. For instance, mapped information regarding the relative abundance of surfactants may be helpful in the design of ship and aircraft based experiments.

Acknowledgments Participants at Los Alamos National Laboratory and New Mexico Tech thank the U.S. Department of Energy SciDAC program (Scientific Discovery for Advanced Computing), and specifically its ACES4BGC project (Applying Computationally Efficient Schemes for Biogeochemical Cycles). SMB was supported by the Office of Science Biological and Environmental Research division of the U.S. Department of Energy, as part of an Earth System Modeling Program. Additionally, contributions by AAF and LMR were supported by NSF grants OCE-1129580 and AGS-1360645. JKM and RTL acknowledge support from the DOE Office of Biological and Environmental Research, Grant ER65358. Validation exercises were conducted as part of the DOE marine biogeochemistry Benchmarking and Feedbacks effort.

Open Access This article is distributed under the terms of the Creative Commons Attribution 4.0 International License (http:// creativecommons.org/licenses/by/4.0/), which permits unrestricted use, distribution, and reproduction in any medium, provided you give appropriate credit to the original author(s) and the source, provide a link to the Creative Commons license, and indicate if changes were made.

\section{References}

Adamson AW (1960) Physical chemistry of surfaces. Interscience, Easton

Adamson AW, Gast AP (1997) Physical chemistry of surfaces. Wiley, New York

Aluwihare LI, Repeta DJ, Chen RF (1997) A major biopolymeric component to dissolved organic carbon in surface sea water. Nature 387:166-169 
Aluwihare LI, Repeta DJ, Pantoja S, Johnson CG (2005) Two chemically distinct pools of organic nitrogen accumulate in the ocean. Science 308:1007-1010

Babak VG, Skotnikova EA, Lukina IG, Pelletier S, Hubert P, Dellacherie E (2000) Hydrophobically associating alginate derivatives: Surface tension properties of their mixed aqueous solutions with oppositely charged surfactants. J Colloid Interf Sci 225:505-510

Baeza R, Sanchez CC, Pilosof AMR, Patino JM (2005) Interactions of polysaccharides with $\beta$ lactoglobulin adsorbed films at the air-water interface. Food Hydrocoll 19:239-248

Barger WR, Means JC (1985) Clues to the structure of marine organic material from the study of physical properties of surface films. In: Sigleo AC, Hattori A (eds) Marine and estuarine Geochemistry. Lewis, Chelsea

Benner R (2002) Chemical composition and reactivity. In: Hansell DA, Carlson CA (eds) Biogeochemistry of marine dissolved organic matter. Academic Press, San Diego

Benner R, Kaiser K (2003) Abundance of amino sugars and peptidoglycan in marine particulate and dissolved organic matter. Limnol Oceanogr 48:118-128

Bhosle NB, Bhaskar PV, Ramachandran S (1998) Abundance of dissolved polysaccharides in the oxygen minimum layer of the northern Indian Ocean. Mar Chem 63:171-182

Blanchard D (1975) Bubble scavenging and the water-to-air transfer of organic material in the sea. Adv Chem Ser 145:360-387

Blanchard D (1989) The ejection of drops from the sea and their enrichment with bacteria ad other materials: a review. Estuaries 12:127-137

Borch NH, Kirchman DL (1997) Concentration and composition of dissolved combined neutral sugars (polysaccharides) in seawater determined by HPLC-PAD. Mar Chem 57:85-95

Brzozowska AM, Duits MHG, Mugele F (2012) Stability of stearic acid monolayers on Artificial Sea Water. Colloids Surf A 407:38-48

Burrows SM, Ogunro O, Frossard AA, Russell LM, Rasch PJ, Elliott S (2014) A physically-based framework for modeling the organic fractionation of sea spray aerosol from bubble film Langmuir equilibria. Atmos Chem Phys 14:13601-13629

Carlson CA (2002) Production and removal processes. In: Hansell DA, Carlson CA (eds) Biogeochemistry of marine dissolved organic matter. Academic Press, San Diego

Carslaw KS, Lee LA, Reddington CL, Pringle KJ, Rap A, Forster PM, Mann GW, Spracklen DV, Woodhouse MT, Regayne LA, Pierce JR (2013) Large contribution of natural aerosols to uncertainty in indirect forcing. Nature 503:67-71

Chin WC, Orellana MV, Verdugo P (1998) Spontaneous assembly of marine dissolved organic matter into polymer gels. Nature 391:568-572

Christodoulou AP, Rosano HL (1968) Effect of pH and nature of monovalent cations on surface isotherms of saturated C16 to C22 soap monolayers. In: Molecular Association in Biological and Related Systems. Adv Chem 84:210-234

Cunliffe M, Upstill-Goddard RC, Murrell JC (2011) Microbiology of aquatic surface microlayers. FEMS Microbiol Rev 35:233-246
Damodaran S, Razumovsky L (2003) Competitive adsorption and thermodynamic incompatibility of mixing of beta-casein and gum arabic at the air-water interface. Food Hydrocoll 17:355-363

Delmas RP, Parrish CC, Ackman RG (1984) Determination of lipid class concentrations in seawater by thin-layer chromatography with flame ionization detection. Anal Chem 56:1272-1277

Dittmar T, Kattner G (2003) Recalcitrant dissolved organic matter in the ocean: major contribution of small amphiphilics. Mar Chem 82:115-123

Dittmar T, Fitznar HP, Kattner G (2001) Origin and biogeochemical cycling of organic nitrogen in the eastern Arctic Ocean as evident from D- and L-amino acids. Geochim Cosmochim Acta 65:4103-4114

Elliott S (2009) Dependence of DMS global sea-air flux distribution on transfer velocity and concentration field type. J Geophys Res 114:G02001

Elliott S, Maltrud M, Reagan M, Moridis G, Cameron-Smith P (2011) Marine methane cycle simulations for the period of early global warming. J Geophys Res 116:G01010

Elliott S, Deal C, Humphries G, Hunke E, Jeffery N, Jin M, Levasseur M, Stefels J (2012) Pan-Arctic simulation of coupled nutrient-sulfur cycling due to sea ice biology. J Geophys Res 117:JG001649

Elliott S, Burrows S, Deal C, Liu X, Long M, Ogunro O, Russell LM, Wingenter O (2014) Prospects for simulating macromolecular surfactant chemistry at the ocean-atmosphere boundary. Environ Res Lett 9:064012

Elliott S, Jeffery N, Hunke E, Deal C, Jin M, Ostreicher S (2015) Strategies for development of global sea ice organic chemistry mechanisms. J Adv Mod Earth Sys, in prep

Frew NM, Goldman JC, Dennet MR, Johnson AS (1990) Impact of phytoplankton generated surfactants on air-sea gas exchange. J Geophys Res 95:3337-3352

Frossard AA, Russell LM, Long MS, Burrows SM, Elliott SM, Kieber DJ, Keene WC, Bates TS, Quinn PK (2014) Sources and composition of submicron organic mass in marine aerosol particles. J Geophys Res 119:JD021913

Fuentes E, Coe H, Green D, De Leeuw G, McFiggans G (2010) Laboratory-generated primary marine aerosol via bubble bursting and atomization. Atmos Meas Tech 3:141-162

Gagosian R, Stuermer D (1977) The cycling of biogenic compounds and their diagenetically transformed products in seawater. Mar Chem 5:605-632

Gagosian RB, Zafiriou OC, Peltzer ET, Alford JB (1982) Lipids in aerosols from the tropical North Pacific - temporal variability. J Geophys Res 87:1133-1144

Gantt B, Meskhidze N, Facchini MC, Rinaldi M, Ceburnis D, O'Dowd CD (2011) Wind speed dependent size-resolved parameterization for the organic mass fraction of sea spray aerosol. Atmos Chem Phys 11:8777-8790

Garrett WD (1967) The organic chemical composition of the ocean surface. Deep Sea Res 14:221-227

Goldberg SJ, Carlson CA, Hansell DA, Nelson NB, Siegel DA (2009) Temporal dynamics of dissolved combined neutral sugars and the quality of dissolved organic matter in the Northwestern Sargasso Sea. Deep Sea Res I 56:672-685

Goldberg SJ, Carlson CA, Brzezinski M, Nelson NB, Siegel DA (2011) Systematic removal of neutral sugars within 
dissolved organic matter across ocean basins. Geophys Res Lett 38:GL048620

Gong SL (2003) A parameterization of sea-salt aerosol source function for sub- and super-micron particles. Glob Biogeochem Cycles 17:GB002079

Graham DE, Phillips MC (1979) Proteins at liquid interfaces: II. Adsorption isotherms. J Colloid Interf Sci 70:415-426

Gregg WW, Ginoux P, Schopf PS, Casey NW (2003) Phytoplankton and iron: validation of a global three-dimensional ocean biogeochemical model. Deep Sea Res II 50:3143-3169

Hansell DA, Carlson CA, Schlitzer R (2012) Net removal of major marine dissolved organic carbon fractions in the subsurface ocean. Glob Biogeochem Cycles 26:GB1016

Hoffman E, Duce RA (1976) Factors influencing the organic chemical content of marine aerosols: a laboratory study. J Geophys Res 81:3667-3670

Hung CC, Tang D, Warnken KW, Santschi PH (2001) Distributions of carbohydrates, including uronic acids, in estuarine waters of Galveston Bay. Mar Chem 73:305-318

Kaiser K, Benner R (2009) Biochemical composition and size distribution of organic matter at the Pacific and Atlantic time-series stations. Mar Chem 113:63-77

Kanicky JR, Shah DO (2002) Effect of degree, type and position of unsaturation on the $\mathrm{pKa}$ of long-chain fatty acids. J Colloid Int Sci 256:201-207

Kattner G, Gercken G, Hammer KD (1983) Development of lipids during a spring plankton bloom in the northern North Sea. Mar Chem 14:163-173

Kujawinsky EB, Farrington JW, Moffett JW (2002) Evidence for grazing mediated production of dissolved surface-active material by marine protists. Mar Chem 77:133-142

Kumar M (2000) A review of chitin and chitosan applications. React Funct Polym 46:1-27

Kuznetsova M, Lee C, Aller J, Frew N (2004) Enrichment of amino acids in the sea surface microlayer at coastal and open ocean sites in the North Atlantic Ocean. Limnol Oceanogr 49:1605-1619

Laidler KJ (1965) Chemical kinetics. McGraw-Hill, New York

Lapina $\mathrm{K}$ et al (2011) Investigating organic aerosol loading in the remote marine environment. Atmos Chem Phys 11:8847-8860

Lee C, Bada J (1977) Dissolved amino acids in the equatorial Pacific, the Sargasso Sea and Biscayne Bay. Limnol Oceanogr 22:502-510

Letscher RT, Moore JK, Teng YC, Primeau F (2015) Variable $\mathrm{C}: \mathrm{N}$ : P stoichiometry of marine dissolved organic matter cycling in the Community Earth System Model. Biogeosci 12:209-221

Liss PS (1975) Chemistry of the sea surface microlayer. In: Riley J, Skirrow G (eds) Chemical oceanography. Academic Press, London

Liss PS, Watson AJ, Bock EJ, Jahne B, Asher WE, Frew NM, Hasse L, Korenowski GM, Merlivat L, Phillips LF, Schluessel P, Woolf DK (1997) Physical processes in the microlayer and the air-sea exchange of trace gases. In: Liss PS, Duce RA (eds) The sea surface and global change. Cambridge University Press, Cambridge

Loh AN, Canuel EA, Bauer JE (2008) Potential source and diagenetic signatures of oceanic dissolved and particulate organic matter as distinguished by lipid biomarker distributions. Mar Chem 112:189-202

Long MS, Keene WC, Kieber DJ, Erickson DJ, Maring H (2011) A sea-state based source function for size-and composition-resolved marine aerosol production. Atmos Chem Phys 11:1203-1216

Longhurst AR (1998) Ecological geography of the sea. Academic Press, San Diego

Malcolm RL (1990) The uniqueness of humic substances in each of soil, stream and marine environments. Anal Chim Acta 232:19-30

Marty JC, Saliot A, Buat-Menard P, Chesselet R, Hunter KA (1979) Relationship between the lipid compositions of marine aerosols, the sea surface microlayer and subsurface water. J Geophys Res 84:5707-5716

McCarthy M, Hedges J, Benner R (1998) Major bacterial contribution to marine dissolved organic nitrogen. Science 281:231-234

Meskhidze N, Xu N, Gantt B, Zhang Y, Nenes A, Ghan S, Liu X, Easter R, Zaveri R (2011) Global distribution and climate forcing of marine organic aerosol: 1. Model improvements and evaluation. Atmos Chem Phys 11:11689-11705

Modini RL, Russell LM, Deane GB, Stokes MD (2013) Effect of soluble surfactant on bubble persistence and bubble-produced aerosol particles. J Geophys Res 118:1388-1400

Moore JK, Doney SC, Kleypas JA, Glover DM, Fung IY (2002) An intermediate complexity marine ecosystem model for the global domain. Deep Sea Res II 49:403-462

Moore JK, Doney SC, Lindsay K (2004) Upper ocean ecosystem dynamics and iron cycling in a global three-dimensional model. Glob Biogeochem Cycles 18:GB4028

Moore RH, Ingall ED, Sorooshian A, Nenes A (2008) Molar mass, surface tension, and droplet growth kinetics of marine organics from measurements of $\mathrm{CCN}$ activity. Geophys Res Lett 35:GL0033350

Mopper K, Zika RG (1987) Free amino acids in marine rains: evidence for oxidation and potential role in nitrogen cycling. Nature 325:246-249

Mykelstad SM, Skanoy E, Hestmann S (1997) A sensitive and rapid method for analysis of dissolved mono- and polysaccharides in seawater. Mar Chem 56:279-286

Nagata T, Meon B, Kirchman DL (2003) Microbial degradation of peptidoglycan in seawater. Limnol Oceanogr 48:745-754

O’Dowd CD, De Leeuw G (2007) Marine aerosol production: a review of the current knowledge. Philos Trans R Soc A 365:1753-1774

O'Dowd CD, Facchini M, Cavalli F, Ceburnis D, Mircea M, Decesari S, Fuzzi S, Yoon YJ, Putaud JP (2004) Biogenically driven organic contribution to marine aerosol. Nature 431:676-680

Pakulski J, Benner R (1994) Abundance and distribution of carbohydrates in the ocean. Limnol Oceanogr 39:930-940

Parra-Barraza H, Burboa MG, Sanchez-Vazquez M, Juarez J, Goycoolea FM, Valdez MA (2005) Chitosan-cholesterol and chitosan-stearic acid interactions at the air-water interface. Biomacromol 6:2416-2426

Parrish CC, Bodennec G, Macpherson EJ, Ackman RG (1992) Seawater fatty-Acids and lipid classes in an urban and a rural Nova-Scotia inlet. Lipids 27:651-655 
Parsons TR, Takahashi M, Hargrave B (1984) Biological oceanographic processes. Pergamon, Oxford

Russell LM, Hawkins LN, Frossard AA, Quinn PK, Bates TS (2010) Carbohydrate-like composition of submicron atmospheric particles and their production from ocean bubble bursting. Proc Natl Acad Sci USA 107:6652-6657

Shogren R, Biresaw G (2007) Surface properties of water soluble maltodextrin, starch acetates and starch acetates/ alkenylsuccinates. Colloids Surf A 298:170-176

Solomon S, Qin D, Manning M, Chen Z, Marquis M, Averyt KB, Tignor M, Miller HL (2007) Climate change 2007: the physical science basis. Cambridge University Press, Cambridge

Somorjai GA (1972) Principles of surface chemistry. PrenticeHall, Englewood Cliffs

Svenningsson B, Rissler J, Swietlicki E, Mircea M, Bilde M, Facchini M, Decesari S, Fuzzi S, Zhou J, Monster J, Rosenorn T (2006) Hygroscopic growth and critical supersaturations for mixed aerosol particles of inorganic and organic compounds of atmospheric relevance. Atmos Chem Phys 6:1937-1952

Tanoue E (1992) Occurrence and characterization of particulate proteins in the Pacific Ocean. Deep Sea Res 39:743-761

Ter Minassian-Seraga L (1956) Recent work on spread monolayers, adsorption and desorption. J Colloid Sci 11:398-418

Tsai WT, Liu KK (2003) An assessment of the effect of sea surface surfactant on global atmosphere-ocean $\mathrm{CO} 2$ flux. J Geophys Res 108:JC000740

Tuckermann R (2007) Surface tension of aqueous solutions of water soluble organic and inorganic compounds. Atmos Environ 41:6265-6275
Van Mooy BAS, Fredricks HF (2010) Bacterial and eukaryotic intact polar lipids in the eastern subtropical South Pacific: water-column distribution, planktonic sources and fatty acid composition. Geochim Cosmochim Acta 74:6499-6516

Vignati E, Facchini M, Rinaldi M, Scannel C, Ceburnis D, Sciare D, Kanakidou M, Myriokefalitakis S, Dentener F, O'Dowd CD (2010) Global scale emission and distribution of sea-spray aerosol: sea-salt and organic enrichment. Atmos Environ 44:670-677

Wakeham S, Lee C, Hedges JI, Hernes PJ, Peterson ML (1997) Molecular indicators of diagnetic status in marine organic matter. Geochim Cosmochim Acta 61:5363-5369

Wang S, Elliott S, Cameron-Smith P, Maltrud M (2015) Influence of explicit Phaeocystis parameterizations on global distributions of marine dimethyl sulfide. J Geophys Res, in review

Wells ML (2002) Marine colloids and trace metals. In: Hansell DA, Carlson CA (eds) Biogeochemistry of marine dissolved organic matter. Academic Press, San Diego

Wells ML, Goldberg ED (1993) Colloid aggregation in seawater. Mar Chem 41:353-358

Witter AE, Luther GW (2002) Spectrophotometric measurement of seawater carbohydrate concentrations in neritic and oceanic waters from the U.S. Middle Atlantic Bight and Delaware estuary. Mar Chem 77:143-156

Wurl O, Miller L, Vagle S (2011) Production and fate of transparent exopolymer particles in the ocean. J Geophys Res 116:JC007342 